Prepared for the U.S. Department of Energy under Contract DE-AC05-76RL01830

\title{
Demonstration of Recessed Downlight Technologies: Power and Illumination Assessment
}

\author{
SA Parker \\ TA Beeson
}

November 2009

\section{Pacific Northwest}

NATIONAL LABORATORY 


\title{
DISCLAIMER
}

United States Government. Neither the United States Government nor any agency thereof, nor Battelle Memorial Institute, nor any of their employees, makes any warranty, express or implied, or assumes any legal liability or responsibility for the accuracy, completeness, or usefulness of any information, apparatus, product, or process disclosed, or represents that its use would not infringe privately owned rights. Reference herein to any specific commercial product, process, or service by trade name, trademark, manufacturer, or otherwise does not necessarily constitute or imply its endorsement, recommendation, or favoring by the United States Government or any agency thereof, or Battelle Memorial Institute. The views and opinions of authors expressed herein do not necessarily state or reflect those of the United States Government or any agency thereof.

\author{
PACIFIC NORTHWEST NATIONAL LABORATORY \\ operated by \\ BATTELLE \\ for the \\ UNITED STATES DEPARTMENT OF ENERGY \\ under Contract DE-AC05-76RL01830 \\ Printed in the United States of America \\ Available to DOE and DOE contractors from the \\ Office of Scientific and Technical Information, \\ P.O. Box 62, Oak Ridge, TN 37831-0062; \\ ph: (865) 576-8401, fax: (865) 576-5728 \\ email: reports@adonis.osti.gov \\ Available to the public from the National Technical Information Service, \\ U.S. Department of Commerce, 5285 Port Royal Rd., Springfield, VA 22161 \\ ph: (800) 553-6847, fax: (703) 605-6900 \\ email: orders@ntis.fedworld.gov \\ online ordering: http://www.ntis.gov/ordering.htm
}

This document was printed on recycled paper.

$(7 / 09)$ 
PNNL-18860

\section{Demonstration of Recessed Downlight Technologies: Power and Illumination Assessment}

SA Parker

TA Beeson

November 2009

Prepared for the

Federal Energy Management Program United States Department of Energy under Contract DE-AC05-76RL01830

Pacific Northwest National Laboratory

Richland, Washington 99354 



\section{Executive Summary}

Solid state lighting (SSL), specifically light-emitting diodes (LED), has been advancing at a rapid pace, and there are presently multiple products available that serve as direct replacements for traditional luminaires. In this demonstration, conventional recessed lights in a conference room were used to compare conventional incandescent A-lamps, incandescent reflector R-lamps, dimming compact fluorescent lamps (CFL), to an LED replacement product. The primary focus during the study was on light delivered to the task plane as provided by the power required by the lighting system. Vertical illuminance, dimming range, and color shift are also important indicators of lighting quality and are discussed in the report.

The results clearly showed that LEDs, with dimming-capable drivers, are much more efficient than incandescent and CFLs. Further, LEDs provide much smoother and consistent dimming than dimmable CFLs. On the potential negative side, it is important that the dimming switch be identified as compatible with the LED driver. A wide variety of dimmer switches are capable of dimming LEDs down to 15\% of full light output, while select others can be capable of dimming LEDs down to 5\%. In addition, LEDs can be intensive light sources, which can result in uncomfortable glare in some applications and to some occupants. Higher ceiling (9-foot or greater) or non-specular reflectors can act to alleviate the potential for glare.

Figure E-1 illustrates the results of the dimming tests performed. Incandescent 100-Watt A-lamps were used as the baseline lighting system, which were compared to incandescent 65-Watt R-lamps, 20Watt dimmable CFL, and 15-Watt LEDs. While the R-lamps are more efficient than the A-lamps, the CFL and LED options were considerably more efficient. The 20-Watt CFL selected did not provide as much illumination as the original baseline condition. This is likely the result of the optics caused by the different lamp shape within the reflector. To match the initial light level of the 100-Watt incandescent Alamps, it is estimated that a 24- to 28-Watt CFL would be required. The 15-Watt LEDs provided more illumination at full load than the baseline incandescent, making the LED the most efficient and effective option, although at a higher initial cost.

Table E-1 summarizes the basic annualized operating costs associated with each of the lighting technologies. Incandescent lamps, thought of as an inexpensive item, result in high labor costs (because of their short lamp life) as well as high energy costs (because of their low efficacy). While LEDs are initially expensive, annualized operating costs are expected to be inexpensive as a result of the expected long usable life (50,000 hours). Of course, the expected long life is not yet completely validated because of the newness of the technology. 


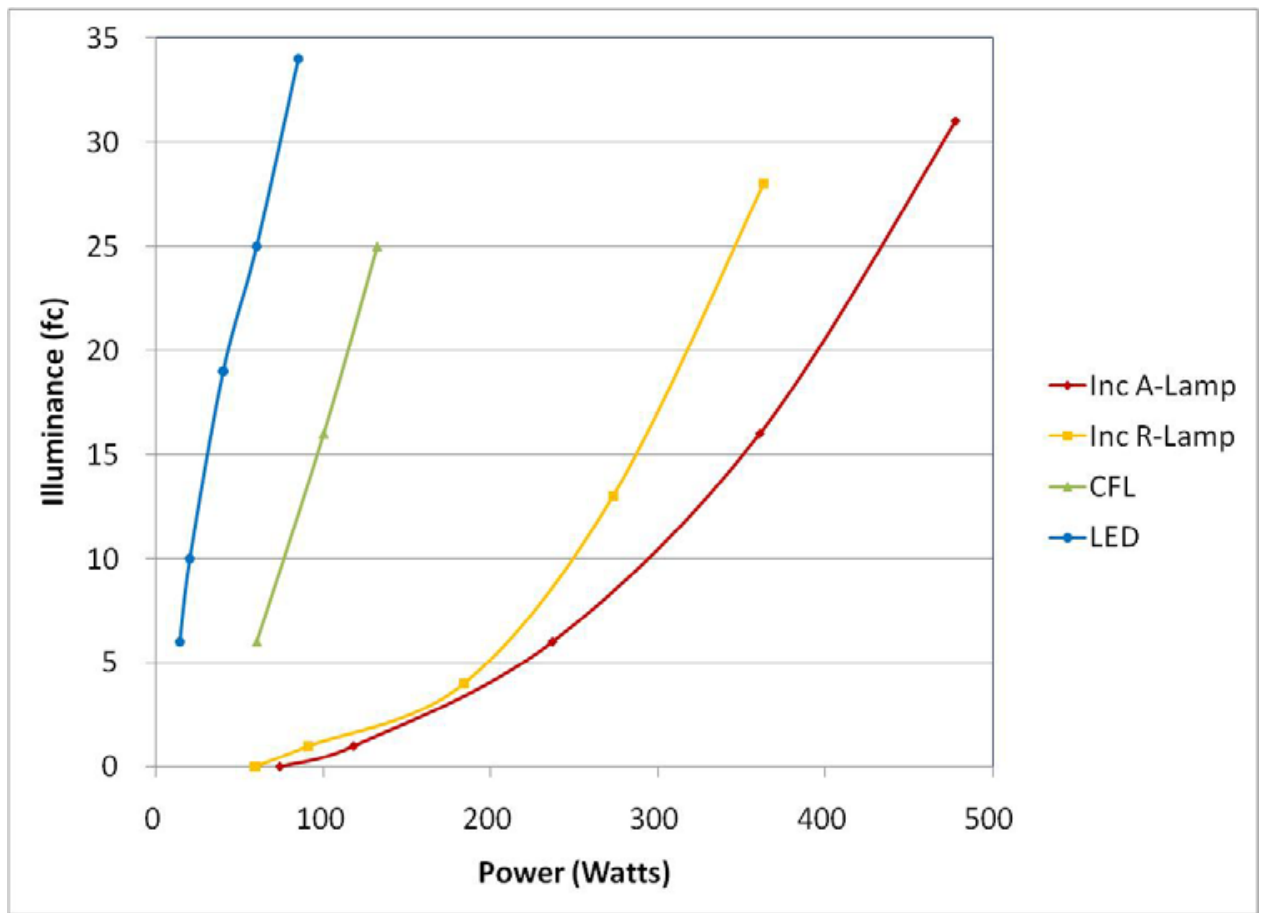

Figure E-1. Illumination versus Power for the Four Lamp Types

Table E-1. Summary of Annualized Costs for the Four Lamp Types

\begin{tabular}{|c|c|c|c|c|c|c|}
\hline \multirow[b]{2}{*}{ Lamp Type } & \multirow{2}{*}{$\begin{array}{c}\text { Rated } \\
\text { Power } \\
\text { (Watts) }\end{array}$} & \multirow{2}{*}{$\begin{array}{c}\text { Measured } \\
\text { Power } \\
\text { (Watts/lamp) }\end{array}$} & \multirow{2}{*}{$\begin{array}{c}\text { Lamp } \\
\text { Cost } \\
(\$ / \text { each })\end{array}$} & \multicolumn{3}{|c|}{$\begin{array}{c}\text { Annualized Operating Costs } \\
(\$ / y r)\end{array}$} \\
\hline & & & & Energy & Materials & Labor \\
\hline A-Lamp & 75 & 79.6 & 0.62 & 96.60 & 1.65 & 33.33 \\
\hline R-Lamp & 65 & 60.5 & 6.89 & 72.60 & 6.89 & 12.50 \\
\hline CFL-Dimmable & 20 & 22.0 & 12.20 & 26.40 & 2.44 & 2.50 \\
\hline LED-Dimmable & 14.8 & 14.2 & $117.50^{\dagger}$ & 17.00 & 4.70 & 0.50 \\
\hline
\end{tabular}

Assumes 2,000 hours per year operation, \$0.10/kWh, 0.25-h/lamp labor, \$50/h labor rate.

${ }^{\dagger}$ Only includes the cost of the replaceable LED module. 


\section{Contents}

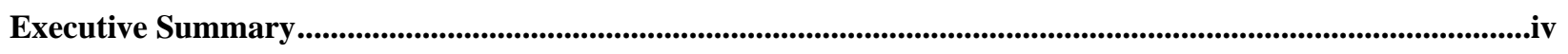

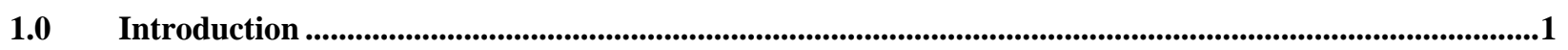

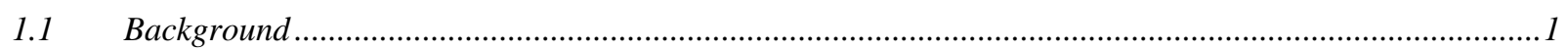

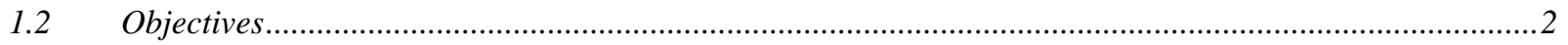

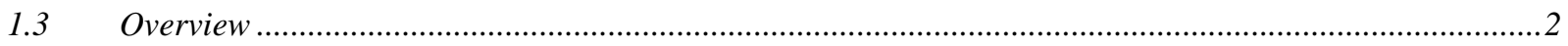

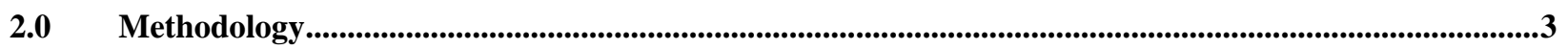

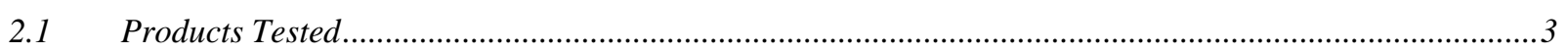

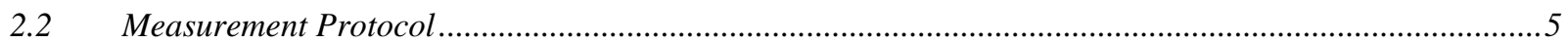

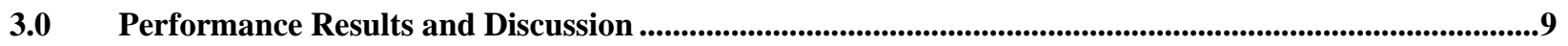

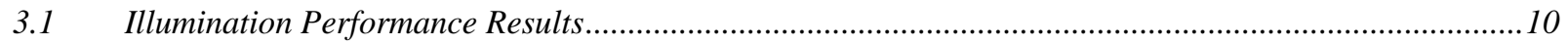

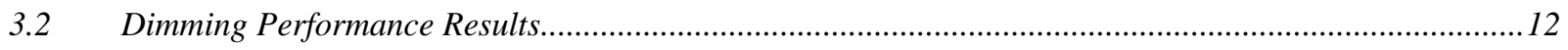

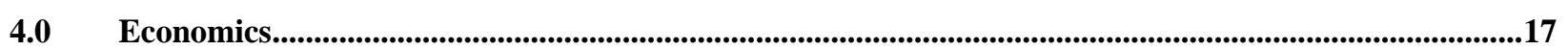

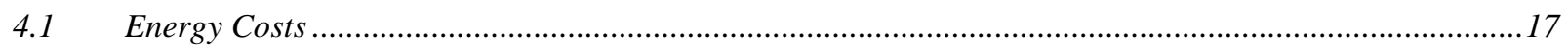

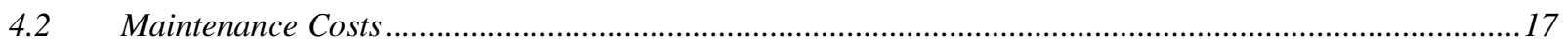

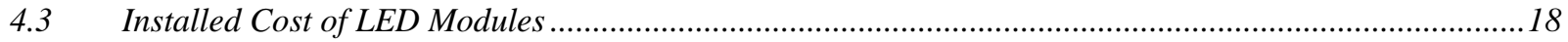




\section{Tables}

Table E-1. Summary of Annualized Costs for the Four Lamp Types...............................................iv

Table 1. Lamp Product Data and Characteristics .......................................................................... 5

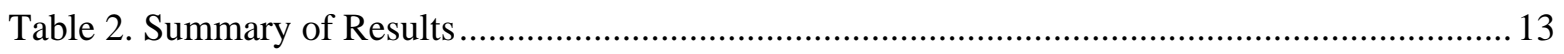

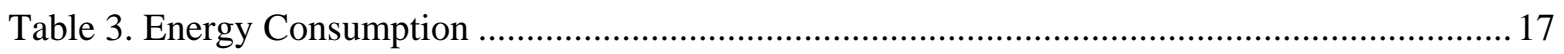

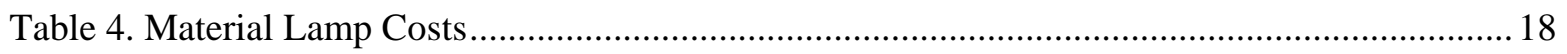

Table 5. Annual Maintenance Cost Estimates by Lamp Type........................................................ 18

Table 6. Equipment Installation Costs for the LED Modules ......................................................... 18

\section{Figures}

Figure E-1. Illumination versus Pwer for the Four Lamp Types .....................................................iv

Figure 1. Incandescent 75-Watt A-lamp (right) and existing recessed housing (left) ......................... 3

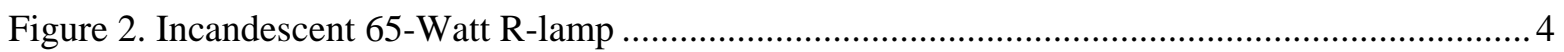

Figure 3. Dimmable compact fluorescent lamp 20-Watt with extender ............................................ 4

Figure 4. LED module with new t-frame housing ……..................................................................... 5

Figure 5. Plan view of the 2400 Stevens, Badger conference room ............................................... 6

Figure 6. Layout of the horizontal measurement points on the conference room table ....................... 7

Figure 7. Layout of the vertical measurement points above the conference room table...................... 8

Figure 8. Power quality analyzer connected at the light switch..................................................... 8

Figure 9. Fluke power quality analyzer and recording computer .................................................... 9

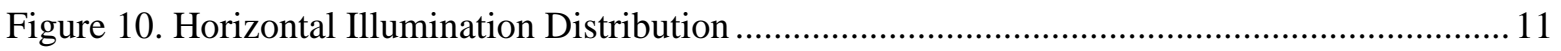

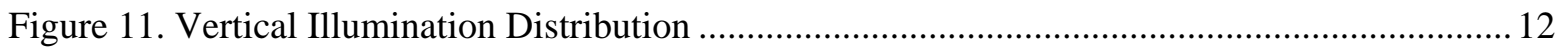

Figure 12. Illuminance versus power performance curve for 75-Watt incandescent A-lamp ............ 13

Figure 13. Illuminance versus power performance curve for 65-Watt incandescent R-lamp............. 14

Figure 14. Illuminance versus power performance curve for 20-Watt dimmable CFL ...................... 14

Figure 15. Illuminance versus power performance curve for 15-Watt LED ..................................... 15

Figure 16. Relative illuminance versus power performance for the 4 lamp types............................. 15

Figure 17. Comparison of color shift during dimming for each lamp type ..................................... 16 


\subsection{Introduction}

This report compares and contrasts four lighting technologies available for use in dimmable downlight applications. Downlights, also known as high-hats, are relatively common in commercial buildings, particularly where dimming is desired. In this demonstration, a small conference room with existing recessed downlight fixtures and dimming capability was used to assess the most commonly used lighting technologies with the purpose of comparing them to a new contender - the light-emitting diode (LED).

Three of the lighting technologies analyzed include traditional incandescent, both A-lamps and Rlamps, and compact fluorescent lamps, which are currently used on a widespread basis. The fourth technology is a fully integrated LED product designed to serve as a direct replacement for traditional recessed downlights.

To perform an effective analysis of the dimming capabilities of each system, quantitative measurements in terms of illuminance and power were collected for each of these technologies. The relationship between power input and light output as illuminance levels on the task plane was recorded to better understand issues associated with compatibility and dimming capabilities.

\subsection{Background}

Recessed downlights are widely used in both residential and commercial applications. Compact fluorescent lamps (CFLs) have not penetrated this market to the same extent as other general lighting applications, and incandescent lamps are still often used in these luminaires because of their straightforward dimming capabilities.

Light emitting diode (LED) technologies have been gaining momentum in the lighting market, but are not yet widely accepted. With recent improvements in LED efficiency, the luminaire replacements rival the efficiency of CFL lamps and provide consumers an even more efficient retrofit option. The LED downlight luminaire also provides greater flexibility than many CFL retrofit options with smooth continuous dimming. In spaces where dimmable downlights are required, LED technologies have the capability to provide variable light levels with reduced power consumption and simplified control.

New products are often designed to replace lighting technologies presently used for general illumination applications. While the purpose of this demonstration is not to endorse one specific make, model or brand, only one LED product was purchased for this specific demonstration. While similar products exist from other manufacturers, the results may not be similar. The Halo LED module selected for this demonstration fit the demonstration requirements and had positive indicators from DOE CALiPER testing ${ }^{1}$. The ML 706830 LED downlight product is a complete unit with an integrated optical system, trim, heat sync, and screw base that is manufactured by Halo. It is designed to be installed in 6inch insulated contact (IC) or non-IC rated downlight housing as a direct replacement for incandescent, halogen, and compact fluorescent recessed can downlights.

\footnotetext{
${ }^{1}$ See http://www1.eere.energy.gov/buildings/ssl/caliper.html for more information on the DOE CALiPER Program.
} 


\subsection{Objectives}

The different lighting technologies evaluated use different mechanisms to achieve light reduction and do not maintain a linear light-to-power relationship. The main objective of this demonstration is to evaluate the relationship between light output and power input for the four different light sources.

Two metrics were used to analyze this relationship. Electric power (Watts) and illumination (footcandles, fc) measurements were recorded for each lamp type. These measurements provided the information necessary to understand the illumination capabilities of each technology when dimmed from full power down to $75 \%, 50 \%, 25 \%$, and lower.

The secondary objectives are to evaluate overall dimming capabilities and potential color shift. If a technology is unable to dim below a certain point, it might not be an effective option for some downlighting applications. Similarly, if there is significant color shift for any of the lighting systems, it too would be worth noting. Finally, the economics of the four technologies are compared as a potential energy-reduction project including energy, maintenance, and retrofit costs.

\subsection{Overview}

This report provides detailed information on the test site and the measurement protocol in Section 2. Section 3 presents the findings and discusses the results from the illumination and power tests. Section 4 discusses the economics for the technologies. Appendix A is the full record of illuminance data collected during the demonstration. Appendix B provides the power and power quality measurements collected during the demonstration. Appendix $\mathrm{C}$ is a reference for measuring equipment used in this study. 


\subsection{Methodology}

This demonstration occurred at the Pacific Northwest National Laboratory. A working conference room at the 2400 Stevens Complex office building served as the demonstration site. The Badger conference room has two lighting systems with a conventional drop ceiling grid. Primary lighting is delivered through four, 2-foot by 4-foot recessed troffer-type fluorescent fixtures. A secondary lighting system consists of six 6-inch recessed can fixtures designed for use with incandescent lamps and controlled with a dimmer switch. This demonstration only concerns the secondary lighting system.

\subsection{Products Tested}

The conventional lamp used in this type of recessed can fixture is a tradition Edison-base A-lamp. While the original fixture installed in the conference room is rated for up to a 100-Watt lamp, 75-Watt lamps were found in place and thus became the conventional baseline for this demonstration. For the purpose of this comparative demonstration, new 75-Watt, inside frosted, A19, incandescent lamps were installed, see Figure 1. A relatively common and somewhat more energy-efficient alternative to the Alamp is a reflector lamp known as the R-lamp. Therefore, the second alternative for this demonstration was a 65-Watt R-lamp, GE model 75R30/FL/65WM, rated at 130-volts, as shown in Figure 2. The 65Watt R-lamp is a rough equivalent to the 75-Watt A-lamp. Although rated for fewer lumens, the reflector is designed to focus the lumens out of the fixture, thereby making it more effective at illuminating the work surface. Operating the 130-volt lamp on a 120-volt circuit will reduce lumen output but would also increase the expected lamp life.

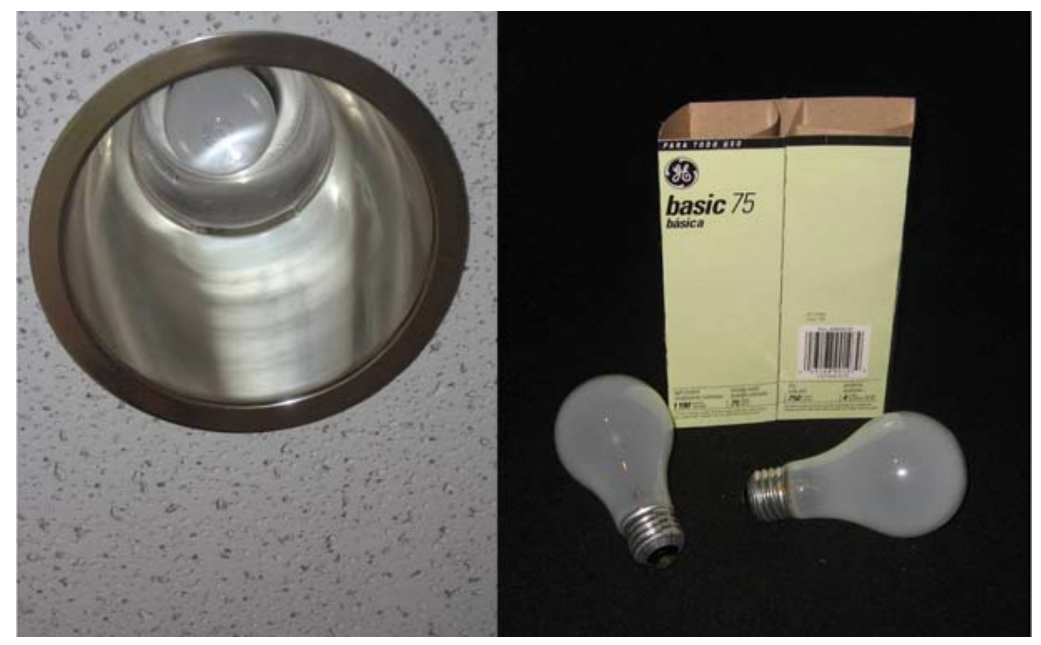

Figure 1. Incandescent 75-Watt A-lamp (right) and existing recessed housing (left) 


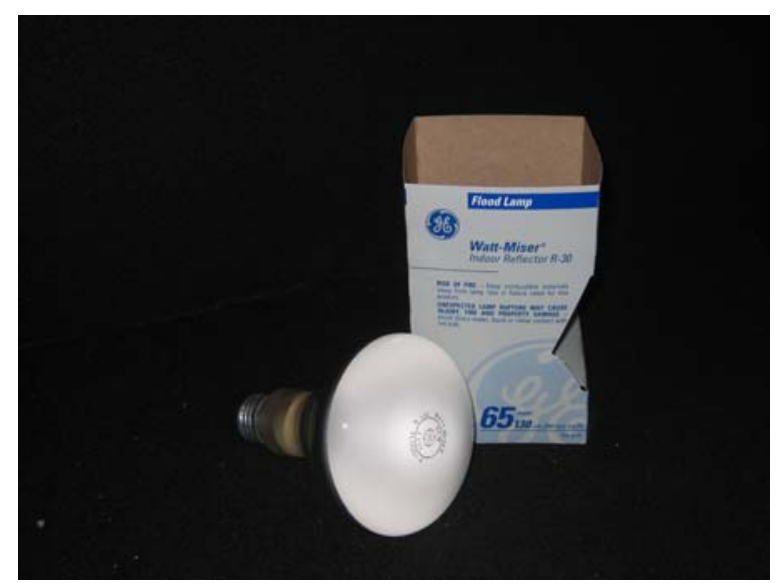

Figure 2. Incandescent 65-Watt R-lamp

A more energy-efficient alternative to incandescent are compact-fluorescent lamps (CFL). The third alternative used in this demonstration was a 20-Watt CFL rated with dimming capability. This lamp size was selected because its rated lumens are close to the original 75-Watt incandescent lamp. Many CFLs are not compatible with dimming; for the purpose of this demonstration, it was important to specify a CFL with dimming capability. The integral ballast was too wide and the base too short to fit in the narrow throat of the reflector in the recessed fixture, therefore a screw-base extender was required to fit the CFL in the existing recessed fixture. Screw base extenders are commonly available through lighting supply sources. Figure 3 shows the CFL lamp with the base extender.

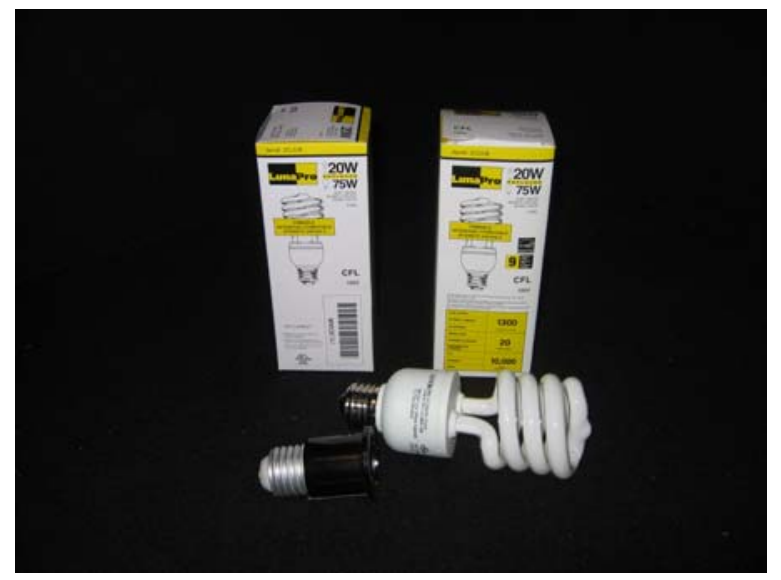

Figure 3. Dimmable compact fluorescent lamp 20-Watt with extender

Finally, a replacement LED luminaire was selected. For this demonstration, a Halo model ML706830 LED module, rated at 14.8 Watts, was selected. The Halo LED module has several reflector options. The Haze reflector, model 494H06 was selected. The Halo LED luminaire is designed with a standard medium screw base than can fit into 6-inch recessed housings. Unfortunately, the Halo unit did not fit into the existing recessed housing in the demonstration conference room. Therefore, a replacement housing, model H750ICAT, compatible with the Halo luminaire, was also installed. Figure 4 shows the LED luminaire and T-frame housing. Table 1 includes the general characteristics of the lamps selected for this demonstration. 


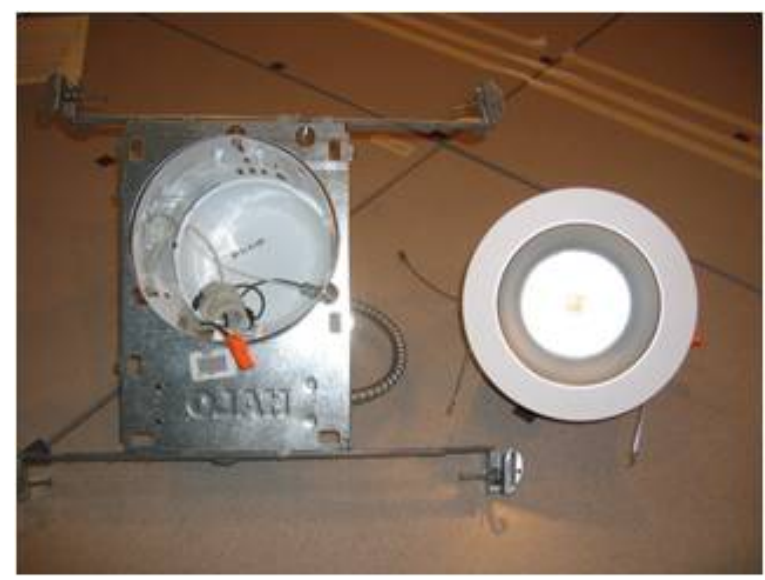

Figure 4. LED module with new t-frame housing

Table 1. Lamp Product Data and Characteristics

\begin{tabular}{|l|c|c|c|c|}
\hline Light Type & Manufacturer/Lamp Code & $\begin{array}{c}\text { Rated } \\
\text { Power } \\
\text { (Watts) }\end{array}$ & $\begin{array}{c}\text { Rated } \\
\text { Luminous Flux } \\
\text { (lumens) }\end{array}$ & $\begin{array}{c}\text { Rated } \\
\text { Life } \\
\text { (hours) }\end{array}$ \\
\hline A-Lamp & GE Basic 75A-120V & 75 & 1190 & 750 \\
\hline R-Lamp & GE Watt Miser 75R30/FL/65-WM-130V & 65 & 725 & 2,000 \\
\hline CFL-Dimmable & LumaPro 20CFL/DIM/27 & 20 & 1300 & 10,000 \\
\hline LED-Dimmable & Halo ML706830 & 14.8 & $650^{*}$ & 50,000 \\
\hline
\end{tabular}

Luminous flux generally represents the total and raw lumen output produced by the lamp. Because LEDs are integral units (i.e., LED, driver and luminaire), the rated lumens also account for fixture efficiency making it not directly comparable to the lumen output of conventional lamps.

\subsection{Measurement Protocol}

The conference room contains 4 large tables assembled together to form one large conference room table. One side of the room, opposite the only doorway, is lined with storage counters. The recessed can lights are mounted directly over the table, as illustrated in Figure 5. The existing recessed can light fixtures focused most of the light on the conference table. Very little direct illumination extends beyond the work surface of the conference room table. For this reason, the measurement protocol was focused on the illumination on and over the conference table. 


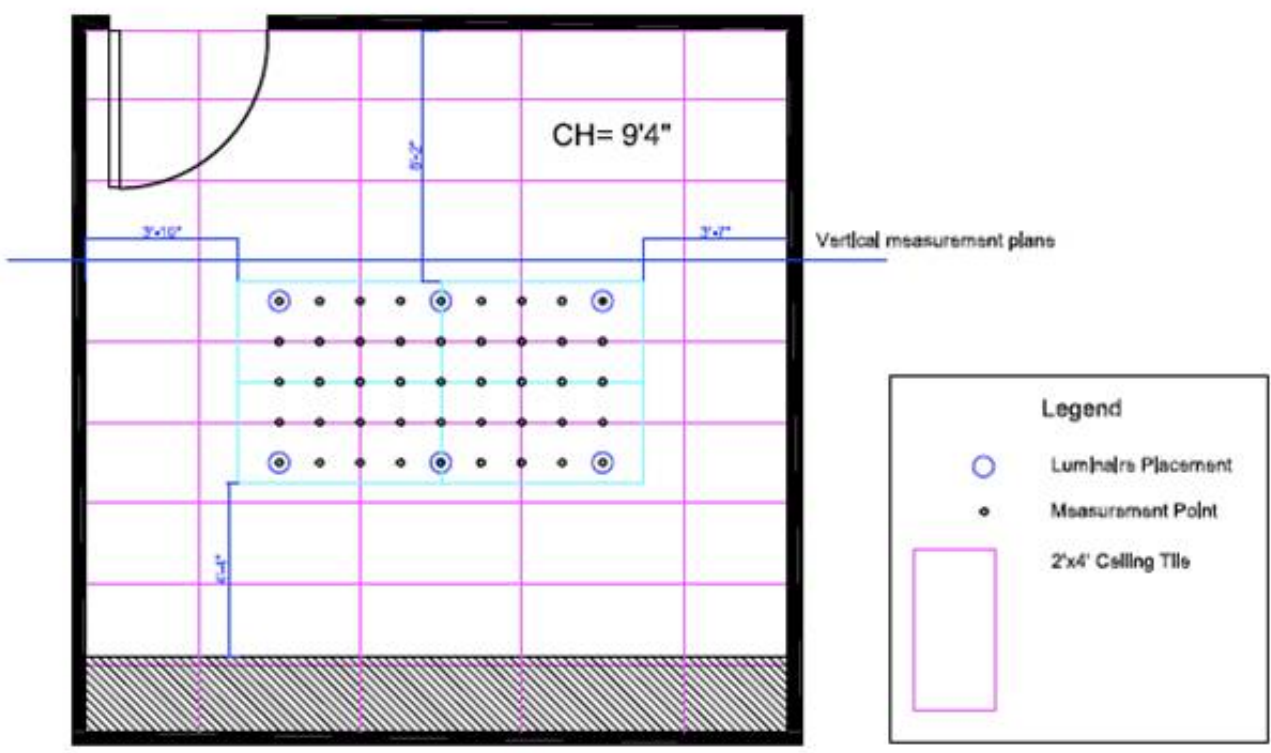

Plan View

Figure 5. Plan view of the 2400 Stevens, Badger conference room

Because the tables would be moved during the course of replacing lamps and changing the luminaires for the LED installation, the exact location of the tables was marked on the floor and measurements were documented. In addition, a grid was marked on the tables for the horizontal illumination measurement locations.

In preparation for the demonstration, the reflectors in existing downlights were cleaned. The lamps to be tested were operated for an appropriate burn-in period prior to the demonstration. The demonstration began by testing the conventional 75-Watt incandescent A-lamps. The tests consisted of both horizontal and vertical illumination measurements, as well as color measurements, with the lighting at full output. Power and power quality measurements were also recorded at the same time. The system was then dimmed to approximately $75 \%$ power input. At the dimmed setting, a smaller set of horizontal illumination and color measurements were recorded along with power and power quality measurements. The dimmed test was repeated for 50\% power input, $25 \%$ power input and the minimum power input setting that could be stabilized with the dimmer and lighting technology. The process was repeated with the 65-Watt R-lamp followed by the 20-Watt CFL.

At the completion of the conventional lamp replacements, the existing recessed cans were replaced with the Halo LED luminaire. This required removing the existing fixture and replacing it with a new housing designed for mounting in a T-frame ceiling grid and capable of supporting the weight of the LED module. Removing the 6 existing fixtures and installing the new housing and LED modules took one maintenance electrician approximately 4 to 5 hours. After the installation and during the commissioning process, it was discovered that the existing dimmer switch was not compatible with the LED modules. As it turned out, the existing dimmer switch used pulse-width modulation for dimming control. The specification sheet that came with the LED module identifies a large assortment of compatible dimmers. The dimmer switch for the room was replaced with a Lutron Skylark SLV-600P-IV, magnetic low voltage 
with forward phase dimming control. Once the LED system was installed and commissioned, the lighting and power measurement process was repeated.

\subsubsection{Lighting Measurements}

Horizontal illumination measurement points were marked directly on the conference table work surface (see Figure 6). Measurement points directly below each luminaire plus $1 / 4,1 / 2$, and $3 / 4$ between each of the luminaires were established. Horizontal illuminance and color measurements were recorded for the 9 by 5 grid for each lighting technology while at full power. During the dimmed tests, a smaller grid of 9 points within the larger grid was specified for the illuminance and color measurements. The smaller grid consisted of the points in columns 1, 3, and 5 and rows 1, 3, and 5, as shown in Figure 6.
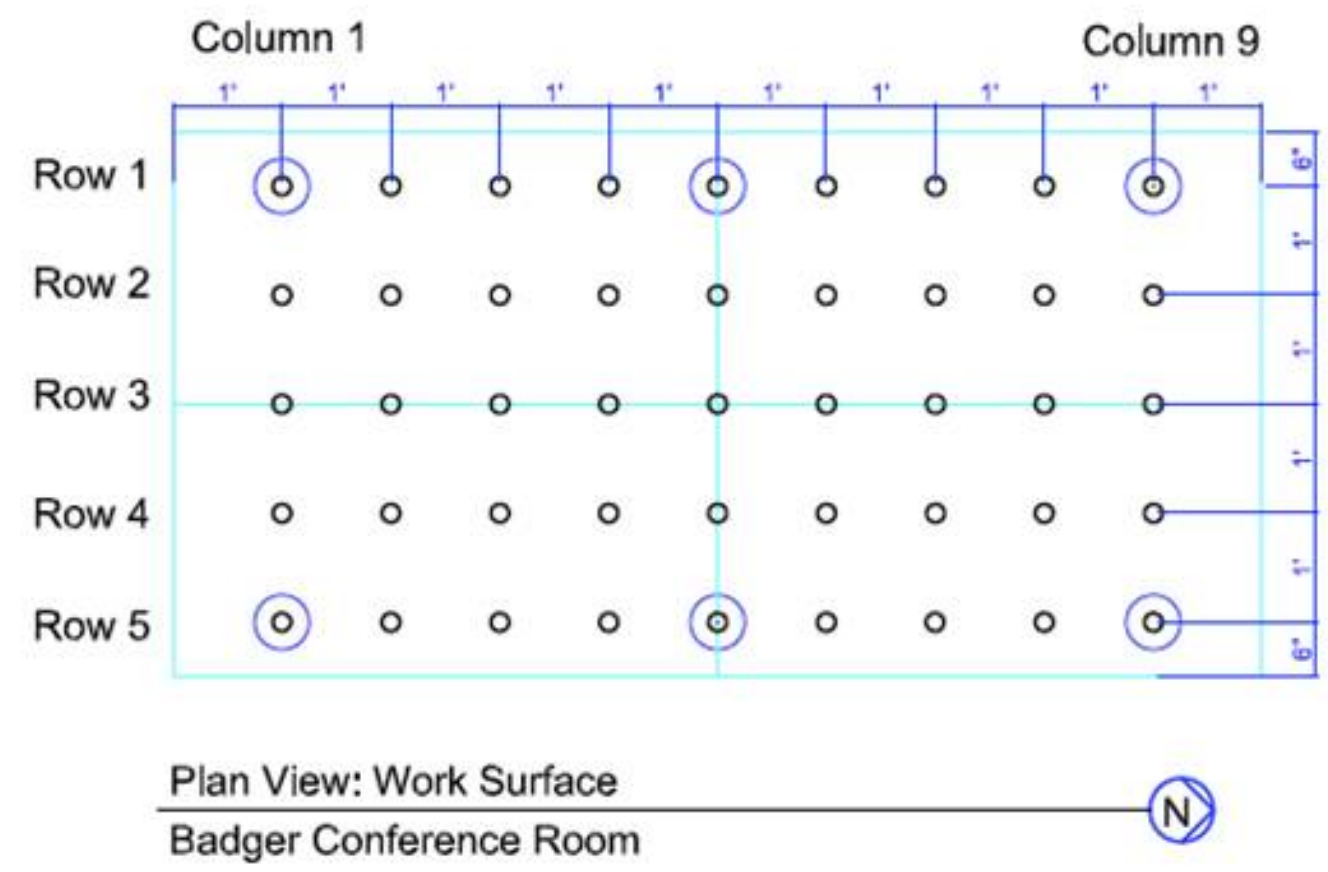

Figure 6. Layout of the horizontal measurement points on the conference room table

Vertical illumination measurements were taken at 3.5-foot, 4.5-foot and 5.5-foot elevations above the floor on a plane parallel to the west wall. Vertical illumination measurements were taken directly under the center of each luminaire plus at $1 / 4,1 / 2$, and $3 / 4$ between the luminaires. The vertical plane was established 1-foot from the center of the west row of luminaires. A line of tape on the table marked the vertical measurement plane. A tripod was used to ensure that the illuminance meter was parallel to the line and not tilted on the $\mathrm{z}$-axis and that the meter remained flush with the vertical plane. A yardstick was used for tripod placement to ensure proper tripod placement and tilt, as shown in Figure 7. A total of 27 vertical illumination measurements were recorded for each lighting technology. 


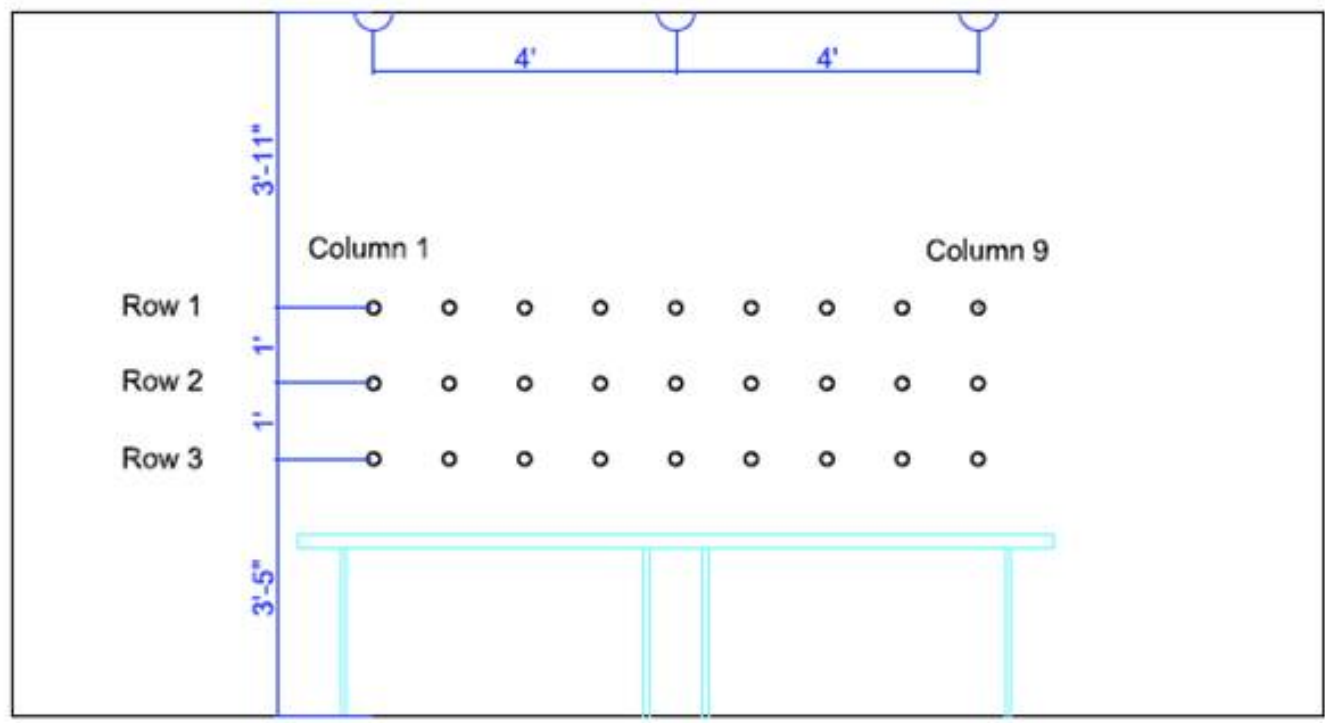

\section{West Elevation}

\section{Badger Conference Room}

Figure 7. Layout of the vertical measurement points above the conference room table

\subsubsection{Power}

Testing for each technology began with the dimmer switch set to full power. The lighting system was given adequate time to stabilize before illumination and power measurements were recorded. The power quality analyzer was connected to the electrical system between the dimmer switch and the lights, as shown in Figures 8 and 9. The power meter reading was used to determine the position of the dimmer switch for the various stages of the dimming tests.

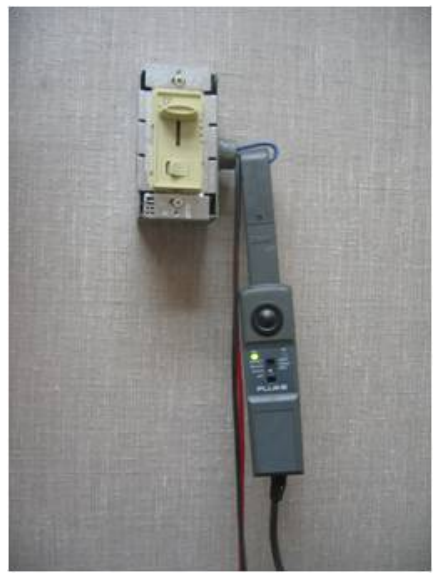

Figure 8. Power quality analyzer connected at the light switch 


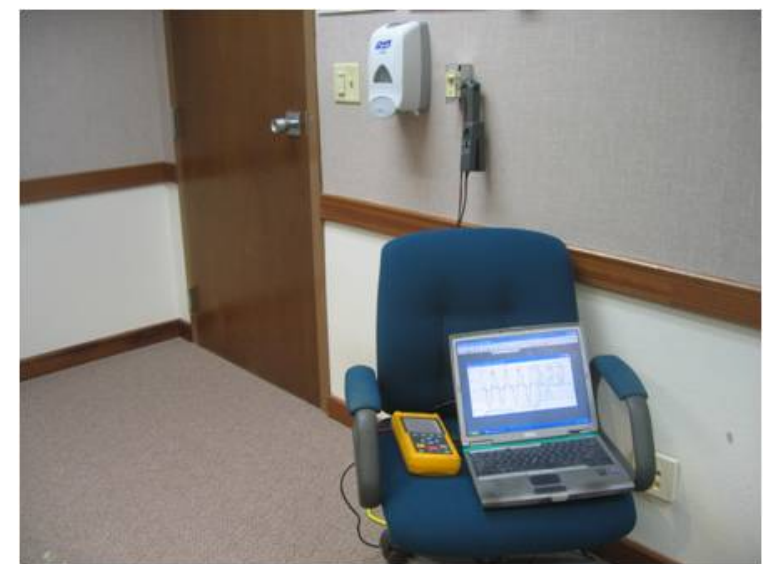

Figure 9. Fluke power quality analyzer and recording computer 


\subsection{Performance Results and Discussion}

One objective of this demonstration was to observe and document the illumination distribution of the four lighting options and document the extent to which the technologies may or may not be equivalent. In addition, the relationship between illumination and power input during the dimming process was to be documented. The results from this demonstration are included in this section. The underlying data is included in Appendix A.

\subsection{Illumination Performance Results}

It should be noted that the original recessed lighting system did not provide adequate illumination for the typical purpose of the conference room. The recessed lighting system did provide illumination across the conference table, but the illumination did not extend much beyond the conference table. This is one of the reasons the measurement protocol area was confined to measurement points on the conference table.

MatLab ${ }^{\circledR}$ software was used to visualize the distribution profiles of the horizontal and vertical illumination data for each of the four lamp types at full power. Figure 10 illustrates the distribution of the horizontal illumination on the conference table, as depicted in Figure 6. Horizontal illumination is used to light objects on the conference table (such as notes placed on the conference table). Figure 11 illustrates the distribution of the vertical illumination above the conference table, as depicted in Figure 7 . Vertical illumination is used to light the sides of objects above the conference table (such as the face of the person sitting at the table). The blue circles represent the approximate location of the six overhead light fixtures. A color scale is used to represent the illumination level from 5 to 40 footcandles.

Figure 10 (a) illustrates the magnitude and distribution of the baseline 75-Watt A-lamp. The illumination levels (in footcandles) range from the mid-20s to the mid-30s, with an average of 31 footcandles. The peak measurements are located under the fixtures, and the minimum measurements are located on the diagonal between fixtures. There is some asymmetry on the right side, which may indicate that one or more fixtures may not have been level in the ceiling grid.

Figure 10 (b) illustrates the 65-Watt R-lamp in the same fixtures. The illumination levels (in footcandles) range from the mid-teens to around 40 , with an average of 28 footcandles. The R-lamp results in a different distribution profile; most notable is that the minimum measurements are directly under the fixtures. The asymmetry, seen with the baseline lamps, is again noted on the right side, which in this case results in the peak illumination measurements. While the color figure may highlight the difference between the 75-Watt A-lamp and the 65-Watt R-lamp, the difference was not visually perceivable.

Figure 10 (c) illustrates the 20-Watt dimmable CFL in the same fixture but using the base extensions illustrated in Figure 3. The illumination level, ranging from 20 to 30 footcandles, with an average of 25 footcandles, was notably lower than the two incandescent options. The illustration also highlights that the distribution peaked in the middle of the table. This change in distribution pattern, while not necessarily undesirable, is likely the result of how the lamp (the source of light) now sits in the reflector. (The light source sits lower in the bowl of the reflector, which will change the distribution of light emitted from the reflector.) 


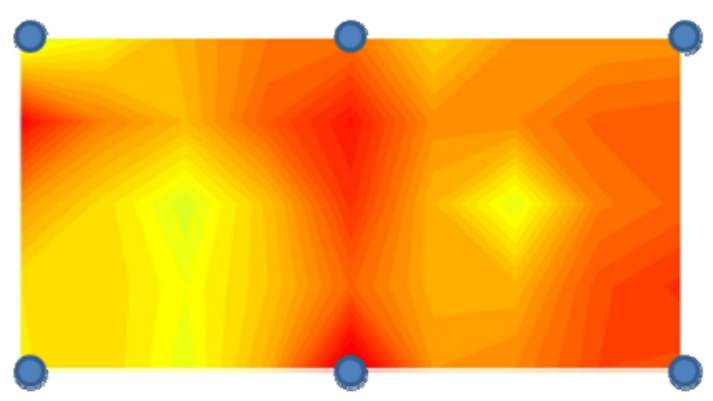

Floure 10(a), In cendescent 75-Wait, A-Lamp

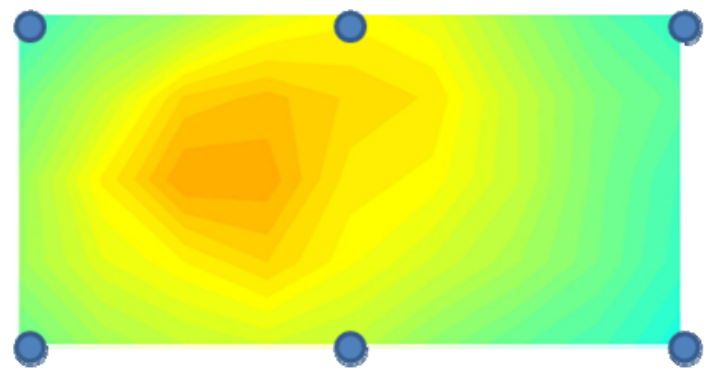

Figure 10(c). Dimming CFL 20-kst

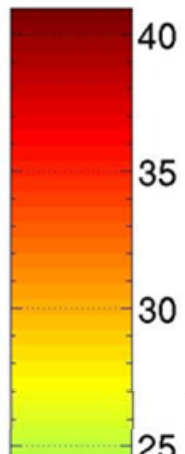

25

Fgure 10(b). Incendescent \&5-Wett, R-Lamp

20

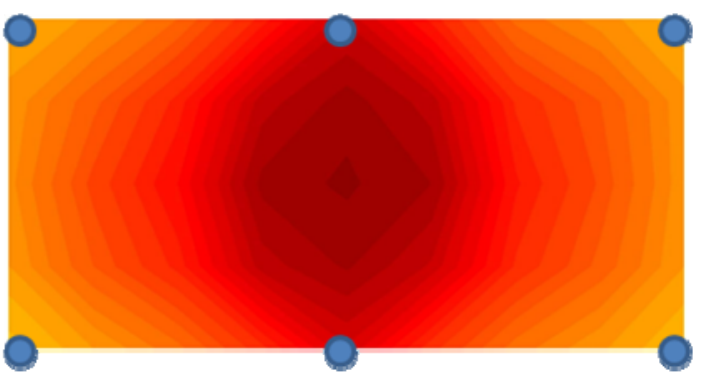

Figure 10(d). LeD Module 15-ven

Figure 10. Horizontal Illumination Distribution

Figure 10 (d) illustrates the new 15-Watt LED module. The illumination levels range from 29 to 40 footcandles, with an average 34 footcandles. The illumination provided by the LED modules was recognizably greater than the other lamp options. In addition, it was observed that the light extended beyond the conference table, providing some illumination to the conference room walls.

Figure 11 (a) illustrates the magnitude and distribution of the vertical illumination for the baseline 75Watt A-lamp. The vertical illumination levels (in footcandles) range from 8 to 20. The peak measurements are located under the fixtures. Although the top row of measurements is nearly 4-foot below the ceiling, the fixture locations are recognizable.

Figure 11 (b) illustrates the distribution of the vertical illumination for the 65-Watt R-lamp. The distribution profile is similar to the A-lamp but more exaggerated. The peak measurements under the fixtures are more pronounced, and the mid-point between the fixtures shows the absence of illumination. This is the result of the R-lamp's reflector being used to focus the light downward. The difference, however, is not really noticeable to the human eye.

Figure 11 (c) illustrates the distribution of the vertical illumination for the 20-Watt dimmable CFL. The peak measurements are between the fixtures rather than directly under the fixtures. This is likely the result of the new focal pattern emerging from relocating the light source within the reflector (a result of the CFL being a longer lamp and the use of the base extender). Also of note is the overall increase in vertical illumination compared to the other lamp options. The increase in vertical illumination may help 
explain why the 20-Watt CFL did not provide the equivalent horizontal illumination-the illumination is simply redirected.

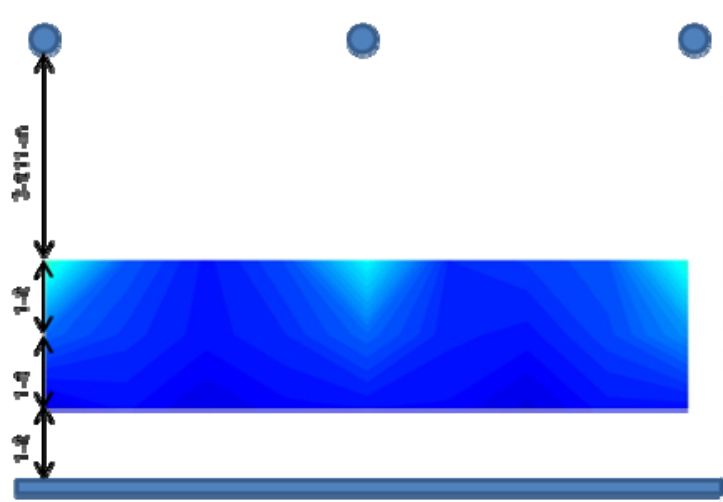

Figure 11(a). Incendescent 75-Watt, A-Lamp

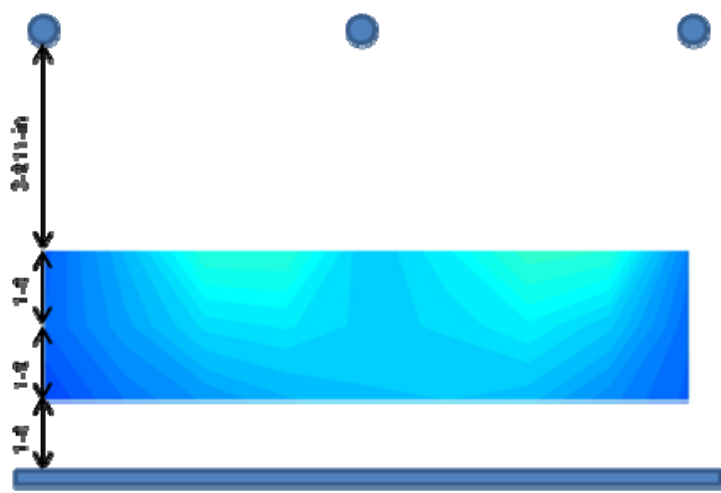

Fioure 11(c). DimmingCFL 20 watt

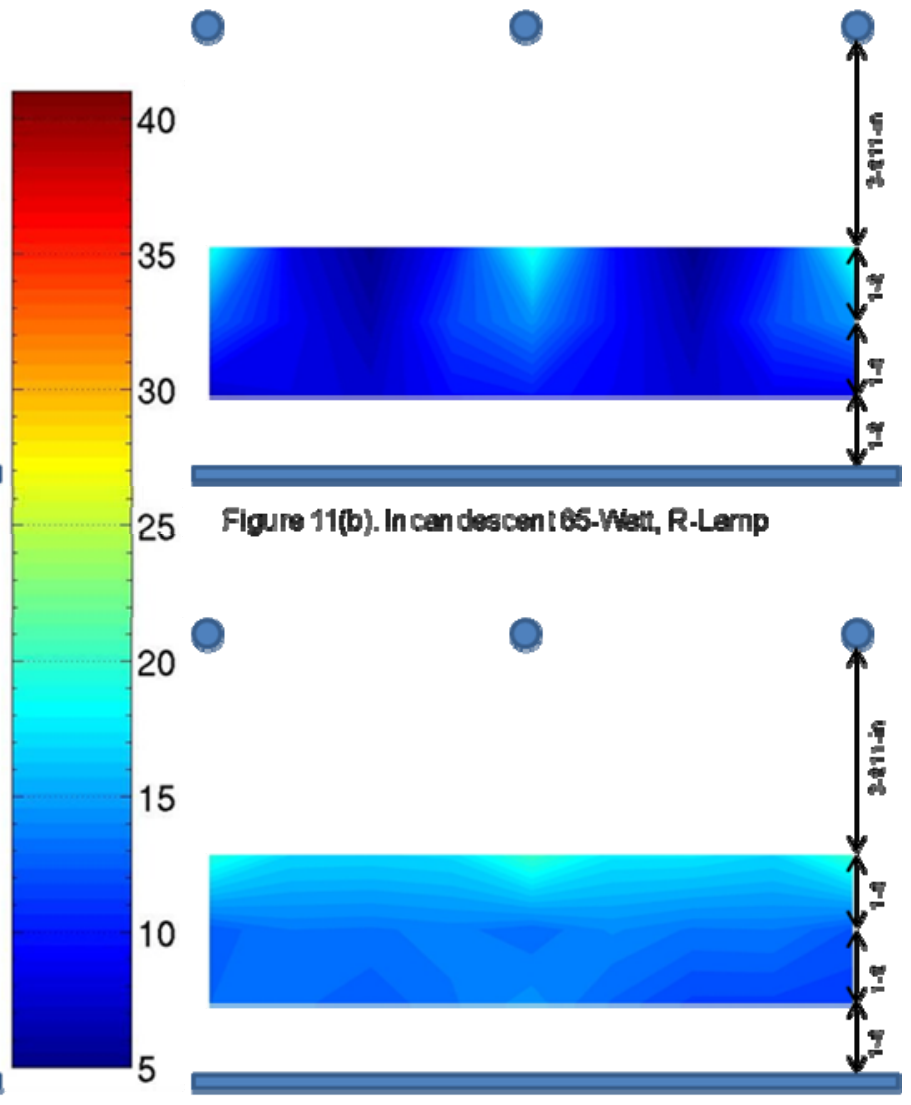

Fioure 11(d). LEDModule 15-hat

Figure 11. Vertical Illumination Distribution

Figure 11 (d) illustrates the distribution of the vertical illumination for the new 15-Watt LED module. In this illustration, the peak measurements are directly under the lamps in Row 1 (3-ft above the table). The profiles for Row 2 (2-ft above the table) and Row 3 (1- $\mathrm{ft}$ above the table) are very uniform. The LED provided greater vertical illumination than the incandescent lamps but less than the 20-Watt CFL. The measurement team did notice a wider overall distribution with the LED modules. However, illumination measurements were not recorded for the conference room walls.

\subsection{Dimming Performance Results}

A summary of the average horizontal illuminance and total power consumption for each of the four lighting systems is included in Table 2 . The table includes the average measured illuminance (in footcandles) and the total measured power (in Watts) for each of the power levels tested. 
Table 2. Summary of Results

\begin{tabular}{|l|c|c|c|c|c|c|c|c|}
\cline { 2 - 8 } \multicolumn{1}{c|}{} & \multicolumn{2}{c|}{ A-Lamp } & \multicolumn{2}{c|}{ R-Lamp } & \multicolumn{2}{c|}{ CFL } & \multicolumn{2}{c|}{ LED } \\
\hline $\begin{array}{l}\text { Power } \\
\text { Level }\end{array}$ & $\begin{array}{c}\text { Illuminance } \\
\text { (fc) }\end{array}$ & $\begin{array}{c}\text { Power } \\
\text { (W) }\end{array}$ & $\begin{array}{c}\text { Illuminance } \\
\text { (fc) }\end{array}$ & $\begin{array}{c}\text { Power } \\
\text { (W) }\end{array}$ & $\begin{array}{c}\text { Illuminance } \\
\text { (fc) }\end{array}$ & $\begin{array}{c}\text { Power } \\
\text { (W) }\end{array}$ & $\begin{array}{c}\text { Illuminance } \\
\text { (fc) }\end{array}$ & $\begin{array}{c}\text { Power } \\
\text { (W) }\end{array}$ \\
\hline $100 \%$ & 31 & 478 & 28 & 363 & 25 & 132 & 34 & 85 \\
\hline $75 \%$ & 16 & 361 & 13 & 273 & 16 & 100 & 25 & 60 \\
\hline $50 \%$ & 6 & 237 & 4 & 184 & 6 & 60 & 19 & 40 \\
\hline $25 \%$ & 1 & 118 & 1 & 91 & & & 10 & 20 \\
\hline Minimum & 0 & 74 & 0 & 59 & & & 6 & 14 \\
\hline
\end{tabular}

The incandescent lamps dimmed seamlessly with the original dimmer that was installed in the conference room. The CFL was only capable of dimming to about $50 \%$ of the maximum power input. When the LED luminaires were installed and failed to dim properly, it was discovered that the dimmer switch used for the demonstration was not on the list of dimmers compatible with the LED lighting system. A compatible dimmer was installed and the tests continued.

The relationship between the input power and average horizontal illumination on the working plane for each of the lighting technologies as they are dimmed is shown in Figures 12 through 15. Figure 16 compares the relative energy performance of each of the technologies through the dimming process. In addition, Figure 17 compares the shift in correlated color temperature (CCT) for each of the lamp types as they are dimmed.

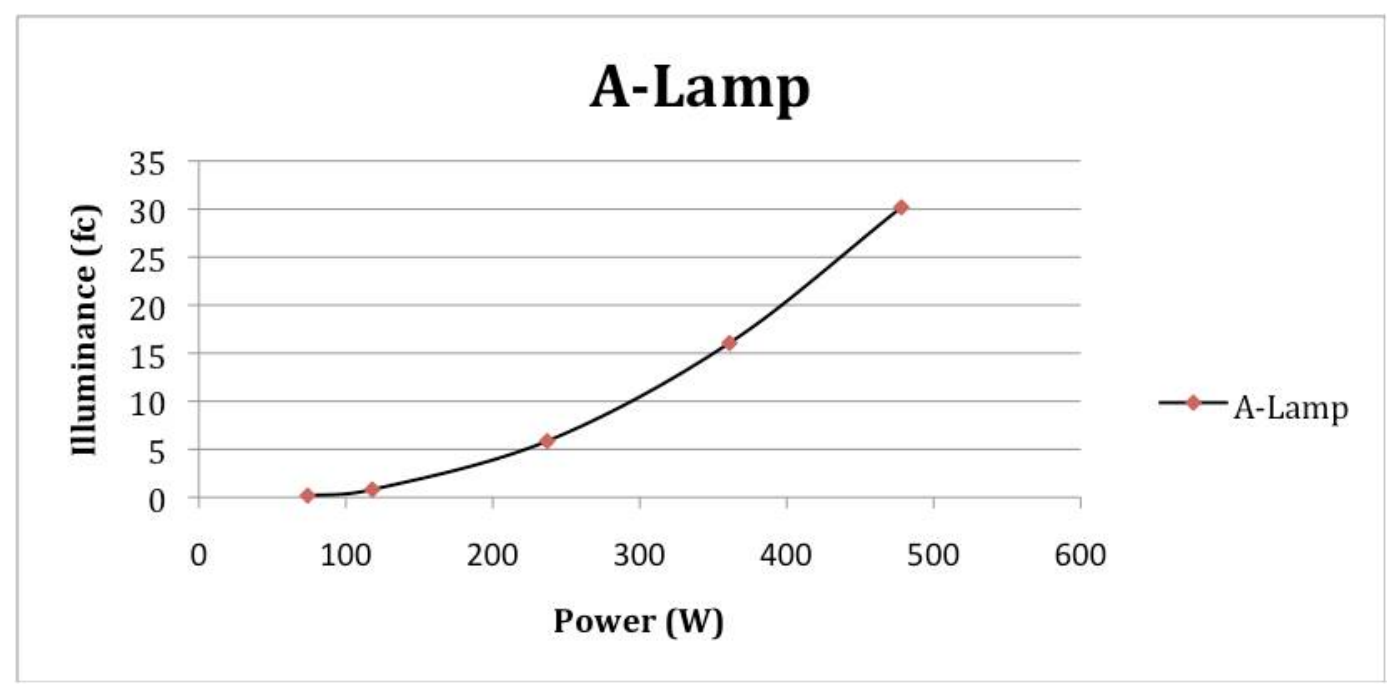

Figure 12. Illuminance versus power performance curve for 75-Watt incandescent A-lamp 


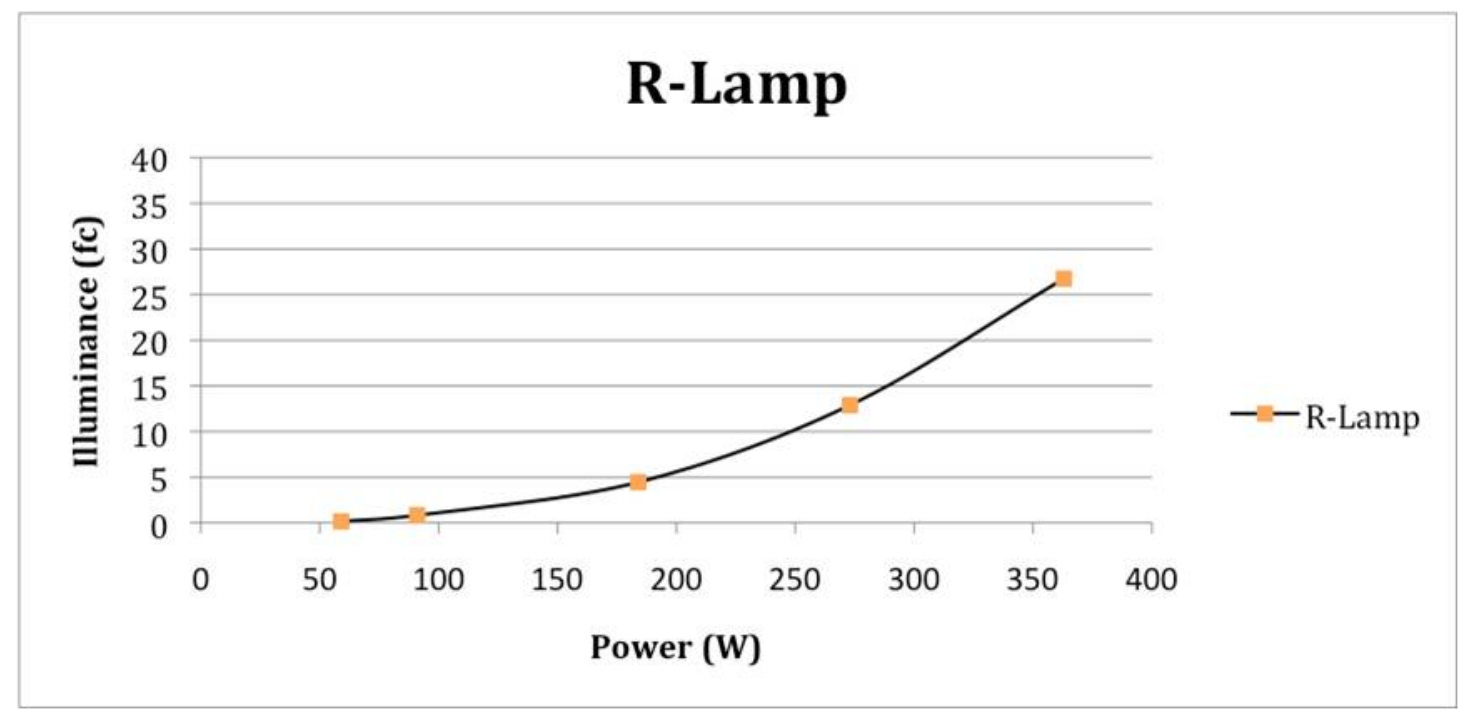

Figure 13. Illuminance versus power performance curve for 65-Watt incandescent R-lamp

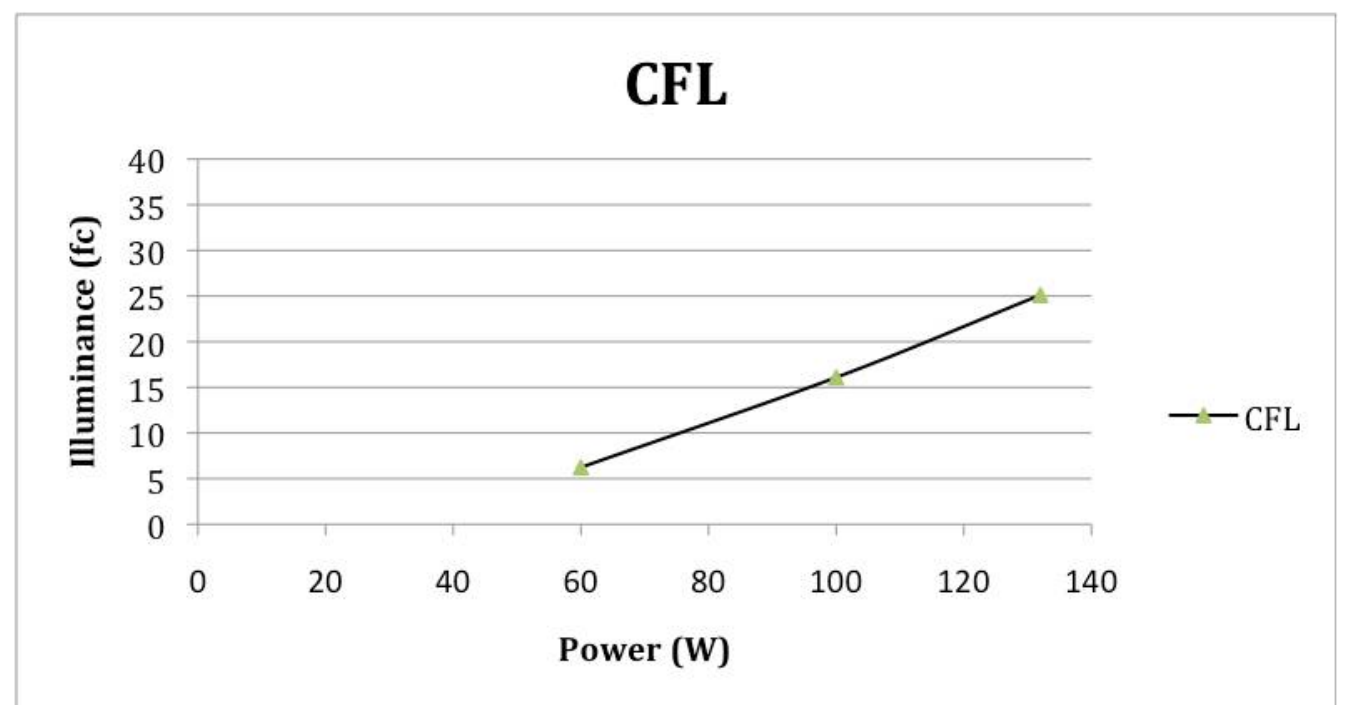

Figure 14. Illuminance versus power performance curve for 20-Watt dimmable CFL 


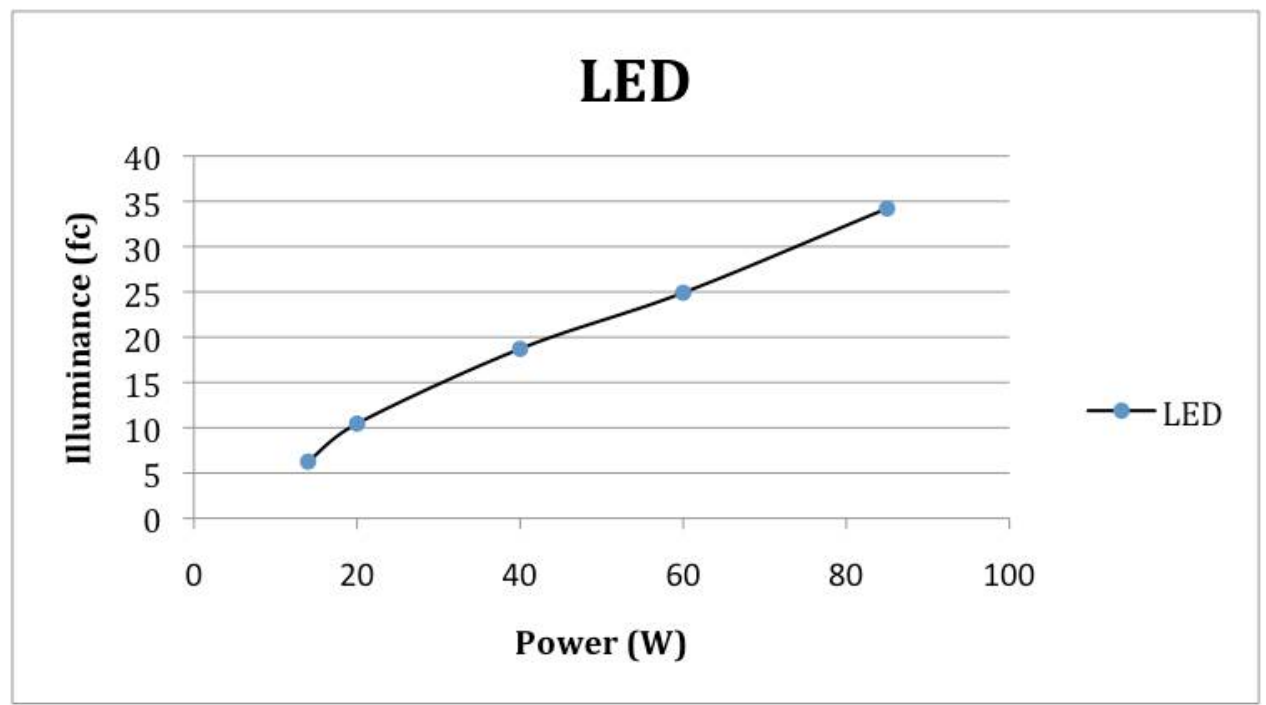

Figure 15. Illuminance versus power performance curve for 15-Watt LED

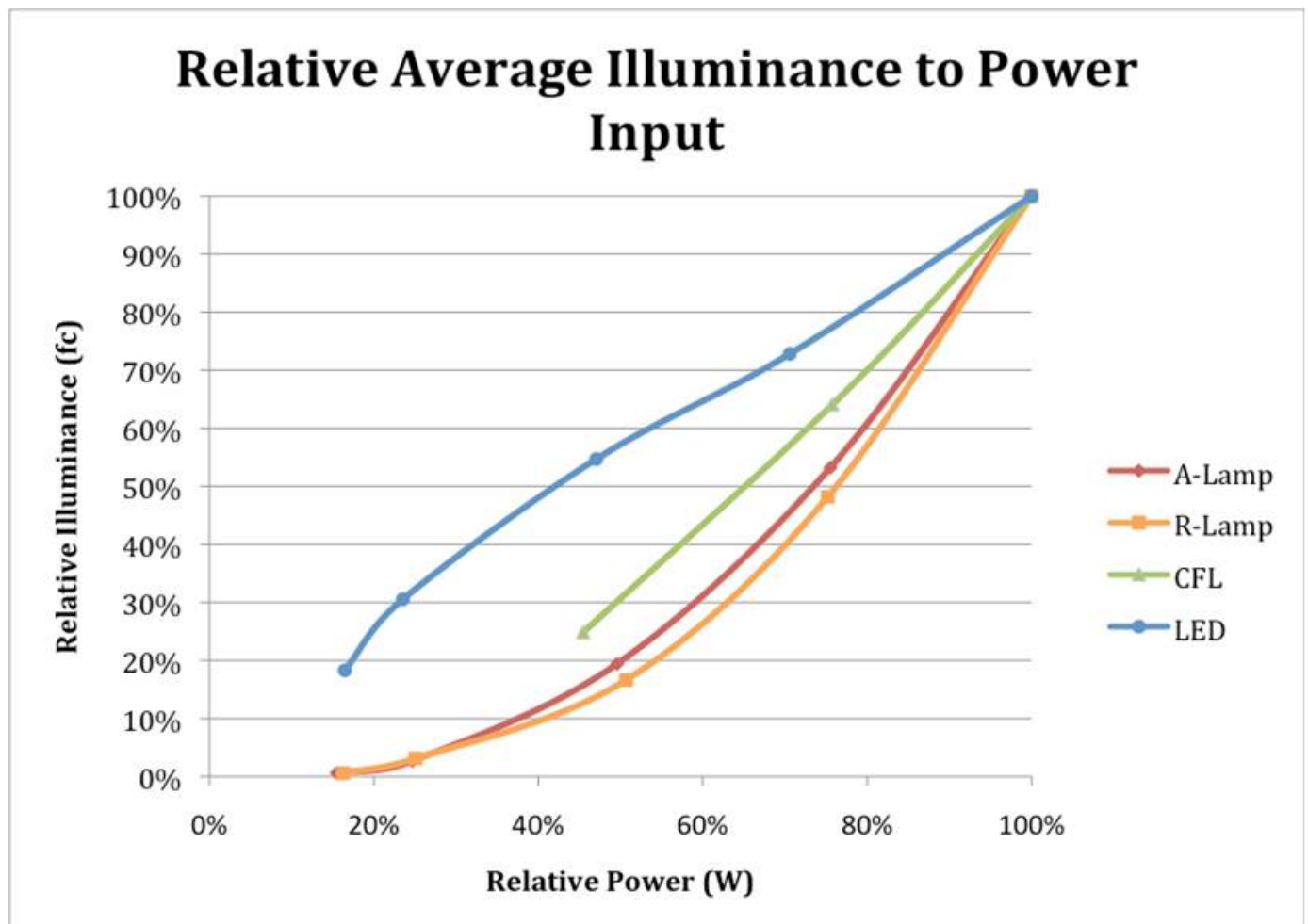

Figure 16. Relative illuminance versus power performance for the 4 lamp types 


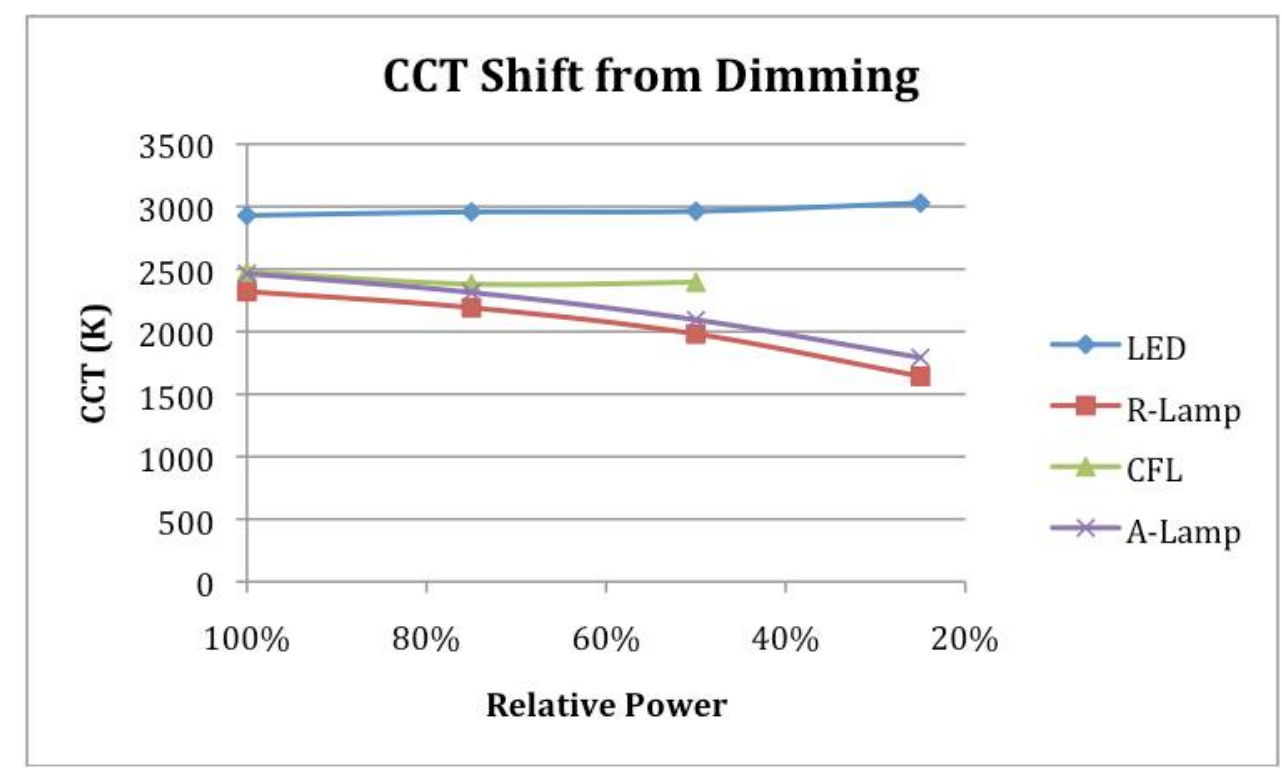

Figure 17. Comparison of color shift during dimming for each lamp type

For the 75-Watt incandescent A-lamp, the lighting system was capable of dimming down to $15 \%$ of full power with a corresponding light level of about $1 \%$ of its initial illumination. For the 65-Watt incandescent R-lamp, the system was capable of dimming down to $16 \%$ of full power with a corresponding light level of about $1 \%$ of its initial illumination. The energy performance of the two incandescent technologies was relatively similar. As shown in Figure 17, both incandescent lamps experienced a notable color shift, becoming warmer, as they were dimmed.

The 20-Watt dimmable CFL, while being more energy efficient than the incandescent lamps, did not deliver the equivalent illumination on the work plane as the incandescent lamps at full power. Instead, the 20-Watt CFL delivered about $19 \%$ less illumination at full power. While the 20-Watt CFL has greater rated lumens than the 75-Watt incandescent A-lamp, the CFL is less effective in the recessed housing. As a result, a 24- to 26-Watt CFL may have been a better alternative if the objective had been to achieve the equivalent illumination level as the 75-Watt incandescent A-lamp. Nevertheless, the dimmable 20-Watt CFL was capable of dimming down to $45 \%$ of full power with a corresponding light level of about $25 \%$ of its initial illumination. With regard to color, the CCT of the CFL was relatively constant over the dimmable range.

Finally, the 15-Watt LED technology produced slightly greater illumination than the 75-Watt incandescent A-lamps at full power. It was also noted by the test staff that the LED module was very intense, making it a potential glare source for occupants working at the conference table. The glare may have been mitigated by selecting another reflector option or application in a room with a higher ceiling level. The LED module did do a better job of distributing the light beyond the limits of the conference table. The LED technology was capable of dimming down to $16 \%$ of full power with a corresponding light level of about $18 \%$ of its initial illumination. It should also be noted that alternative dimmer switches are reportedly capable of allowing the LED technology to dim to as low as $5 \%$ of full power. The LED also experienced very little color shift over the dimmable range. 


\subsection{Economics}

Setting the dimming aside and assessing the four technologies on an economic basis comes down to examining three primary cost factors: energy operating costs, maintenance costs, and installed equipment costs. Table 1, shown previously, identified the rated power requirements for each of the four different lamp types studied. Table 2, also shown previously, summarized the total measured power of the 6-lamp system with each of the four different lamps types.

\subsection{Energy Costs}

Energy consumption is a function of the power required by the lighting system, from Table 2, and the operating hours. Table 3 summarizes the potential energy consumption of the lighting systems, assuming the lamps are operated at full power (no dimming) for different hours of operation. In addition, potential energy operating costs are shown, assuming the lighting system is operated 1,000 hours per year with an average energy cost of $\$ 0.10 / \mathrm{kWh}$.

Table 3. Energy Consumption

\begin{tabular}{|c|c|c|c|c|c|c|}
\hline \multirow[b]{2}{*}{ Lamp Type } & \multirow[b]{2}{*}{$\begin{array}{l}\text { Power } \\
\text { (Watts) }\end{array}$} & \multicolumn{4}{|c|}{$\begin{array}{c}\text { Energy Consumption } \\
(\mathrm{kWh} / \mathrm{yr})\end{array}$} & \multirow[b]{2}{*}{$\begin{array}{c}\text { Energy Cost* } \\
(\$ / y r)\end{array}$} \\
\hline & & $\begin{array}{l}\text { Operation } \\
500 \mathrm{~h} / \mathrm{yr}\end{array}$ & $\begin{array}{l}\text { Operation } \\
1000 \mathrm{~h} / \mathrm{yr}\end{array}$ & $\begin{array}{l}\text { Operation } \\
2000 \mathrm{~h} / \mathrm{yr}\end{array}$ & $\begin{array}{l}\text { Operation } \\
4000 \mathrm{~h} / \mathrm{yr}\end{array}$ & \\
\hline A-Lamp & 478 & 239 & 478 & 956 & 1912 & 96.60 \\
\hline R-Lamp & 363 & 182 & 363 & 726 & 1452 & 72.60 \\
\hline CFL-Dimmable & 132 & 66 & 132 & 264 & 528 & 26.40 \\
\hline LED-Dimmable & 85 & 43 & 85 & 170 & 340 & 17.00 \\
\hline
\end{tabular}

* Assumes operation is $2,000 \mathrm{~h} / \mathrm{yr}$ and energy cost is $\$ 0.10 / \mathrm{kWh}$.

\subsection{Maintenance Costs}

While incandescent lamps are considered inexpensive, they are also short lived. Table 4 summarizes the lamp product data, including material costs for each of the 4 lamp alternatives studied in this project. As shown, the incandescent lamps are the least expensive item and the LED modules appear to be quite expensive. However, when the costs are annualized and include both material and labor costs, the results are reversed, as illustrated in Table 5, with the LED option becoming the least expensive and the incandescent and dimming CFL alternatives being more expensive. Of course, labor costs will vary and, in some cases, might not be appropriate to consider depending on the labor force requirements for changing lamps within a specific facility. 
Table 4. Material Lamp Costs

\begin{tabular}{|l|l|c|c|c|c|c|}
\hline Light Type & Manufacturer & $\begin{array}{c}\text { Product } \\
\text { Code }\end{array}$ & $\begin{array}{c}\text { Rated } \\
\text { Power } \\
\text { (Watts) }\end{array}$ & $\begin{array}{c}\text { Rated } \\
\text { Output } \\
\text { (lumens) }\end{array}$ & $\begin{array}{c}\text { Rated } \\
\text { Life } \\
\text { (hours) }\end{array}$ & $\begin{array}{c}\text { Replacement } \\
\text { Lamp Cost } \\
\text { (\$ each) }\end{array}$ \\
\hline A-Lamp & GE & 5 V599* & 75 & 1190 & 750 & $0.62^{*}$ \\
\hline R-Lamp & GE & 2 F214 & 65 & 725 & 2,000 & $6.89^{*}$ \\
\hline CFL-Dimmable & LumaPro & 2CUU8 & 20 & 1300 & 10,000 & $12.20^{*}$ \\
\hline LED-Dimmable & Halo & ML706830 & 14.8 & 650 & 50,000 & $117.50 \dagger$ \\
\hline
\end{tabular}

Grainger Inc. used for cost source.

$\dagger$ Cost only includes the LED module with driver and does not include ancillary materials required for initial installation.

Table 5. Annual Maintenance Cost Estimates by Lamp Type

\begin{tabular}{|l|c|c|c|}
\hline Light Type & $\begin{array}{c}\text { Material Cost } \\
\text { (\$/lamp/yr) }\end{array}$ & $\begin{array}{c}\text { Labor Cost }^{\dagger} \\
\mathbf{( \$ / l a m p / y r ) ~}\end{array}$ & $\begin{array}{c}\text { Total Operating Costs }^{\ddagger} \\
\text { (\$/lamp/yr) }\end{array}$ \\
\hline A-Lamp & 1.65 & 33.33 & 34.99 \\
\hline R-Lamp & 6.89 & 12.50 & 19.39 \\
\hline CFL & 2.44 & 2.50 & 4.94 \\
\hline LED & 4.70 & 0.50 & 5.20 \\
\hline
\end{tabular}

Estimated = (replacement lamp cost)x(2,000 operating hours/yr)/(rated lamp life)

${ }^{\dagger}$ Estimated $=(\$ 50 / \mathrm{h}$ labor rate $) \times(0.25 \mathrm{~h} / \mathrm{lamp}) \times(2,000$ operating hours/yr $) /($ rated lamp life $)$

₹ Total of annual material and labor costs

\subsection{Installed Cost of LED Modules}

Given the existing condition of the recessed lighting system in this demonstration, changing from incandescent A-lamps to incandescent R-lamps, or even to dimming CFL, only required changing lamps. In these alternatives, the installation cost is minimal and only required purchasing the new lamps.

For the LED alternative, the LED module selected was too large to fit inside the existing lamp housing. Therefore, it was necessary to remove the existing lamp housing and replace with new housing compatible with the LED module selected. Therefore, installation required the use of a license electrician, as well as additional materials. The installed costs, including parts and labor are summarized in Table 6.

Table 6. Equipment Installation Costs for the LED Modules

\begin{tabular}{|l|c|c|r|}
\hline Description & Units & Unit Cost & Total Cost \\
\hline Halo LED Module ML706830 & 6 & $\$ 117.50$ & $\$ 705.00$ \\
\hline Halo Haze Reflector 494H06 & 6 & 24.17 & 145.02 \\
\hline Freight Charge & 1 & 25.70 & 25.70 \\
\hline Halo Recessed Lighting Housing, Non IC, H7T & 6 & 12.02 & 72.12 \\
\hline Lutron, Dimmer, Skylark SLV-600P-IV & 1 & 52.77 & 52.77 \\
\hline Labor, Electrician & 5 & 100.00 & 500.00 \\
\hline Total Installed Cost & & $\mathbf{\$ 1 , 5 0 0 . 6 1}$ \\
\hline
\end{tabular}


The resulting simple payback of the LED modules, compared to the originally-installed incandescent Alamps, is still long, approximately 13 years (assuming 2,000 h/yr operation). However, this is well within the expected usable life of the LED module (25 years, assuming 2,000 h/yr operation). 


\section{Appendix A. Light Measurement Data}


Table A.1. Horizontal Illuminance Measurements (fc)

\begin{tabular}{|c|c|c|c|c|c|}
\hline \multicolumn{6}{|l|}{ Full Power } \\
\hline Dimmer & Leviton & Leviton & Leviton & Leviton* & Lutron \\
\hline Lamp & 75W A-Lamp & 65W R-Lamp & 20W CFL & 15W LED & 15W LED \\
\hline Total Power & 478 Watts & 363 Watts & 132 Watts & 84 Watts & 85 Watts \\
\hline Row 1, Point 1 & 25.5 & 18.4 & 20.1 & 30.3 & 30.4 \\
\hline Row 1, Point 2 & 27.6 & 23.8 & 22.6 & 31.1 & 31.0 \\
\hline Row 1, Point 3 & 30.2 & 29.8 & 24.1 & 32.8 & 32.6 \\
\hline Row 1, Point 4 & 32.0 & 31.9 & 26.5 & 35.1 & 35.1 \\
\hline Row 1, Point 5 & 32.3 & 23.6 & 27.3 & 38.1 & 38.1 \\
\hline Row 1, Point 6 & 28.6 & 26.2 & 26.6 & 35.0 & 35.2 \\
\hline Row 1, Point 7 & 31.0 & 30.2 & 24.0 & 32.2 & 32.4 \\
\hline Row 1, Point 8 & 30.9 & 23.2 & 21.6 & 31.3 & 31.2 \\
\hline Row 1, Point 9 & 31.1 & 16.2 & 19.9 & 30.1 & 30.0 \\
\hline Row 2, Point 1 & 36.0 & 25.0 & 22.3 & 31.1 & 31.1 \\
\hline Row 2, Point 2 & 31.6 & 26.6 & 25.4 & 33.0 & 33.0 \\
\hline Row 2, Point 3 & 29.7 & 28.7 & 28.8 & 35.1 & 35.1 \\
\hline Row 2, Point 4 & 33.1 & 31.6 & 29.4 & 38.4 & 38.5 \\
\hline Row 2, Point 5 & 35.5 & 29.4 & 28.6 & 39.5 & 39.7 \\
\hline Row 2, Point 6 & 31.2 & 29.7 & 28.0 & 38.4 & 38.5 \\
\hline Row 2, Point 7 & 31.4 & 29.2 & 25.4 & 34.8 & 34.8 \\
\hline Row 2, Point 8 & 32.8 & 28.9 & 22.9 & 32.2 & 33.2 \\
\hline Row 2, Point 9 & 33.1 & 23.5 & 21.6 & 31.1 & 31.1 \\
\hline Row 3, Point 1 & 30.8 & 40.1 & 23.8 & 31.3 & 31.3 \\
\hline Row 3, Point 2 & 28.4 & 27.9 & 27.6 & 33.9 & 33.9 \\
\hline Row 3, Point 3 & 26.0 & 25.3 & 30.4 & 35.9 & 36.0 \\
\hline Row 3, Point 4 & 29.4 & 30.2 & 30.2 & 39.6 & 39.6 \\
\hline Row 3, Point 5 & 34.5 & 32.7 & 27.8 & 39.9 & 40.0 \\
\hline Row 3, Point 6 & 29.9 & 29.9 & 27.3 & 39.3 & 39.4 \\
\hline Row 3, Point 7 & 26.3 & 26.7 & 25.4 & 35.4 & 35.5 \\
\hline Row 3, Point 8 & 31.8 & 28.9 & 22.7 & 33.6 & 33.6 \\
\hline Row 3, Point 9 & 32.8 & 30.2 & 20.7 & 31.0 & 31.1 \\
\hline Row 4, Point 1 & 28.1 & 25.8 & 24.0 & 30.9 & 30.9 \\
\hline Row 4, Point 2 & 28.6 & 27.9 & 26.3 & 33.2 & 33.2 \\
\hline Row 4, Point 3 & 27.0 & 26.8 & 27.5 & 35.2 & 35.1 \\
\hline Row 4, Point 4 & 29.2 & 29.6 & 28.7 & 38.5 & 38.5 \\
\hline Row 4, Point 5 & 32.7 & 32.9 & 27.1 & 39.4 & 39.5 \\
\hline Row 4, Point 6 & 30.1 & 31.9 & 25.8 & 38.1 & 38.1 \\
\hline Row 4, Point 7 & 30.0 & 28.7 & 24.3 & 34.7 & 34.8 \\
\hline Row 4, Point 8 & 33.5 & 30.5 & 22.5 & 33.0 & 33.0 \\
\hline Row 4, Point 9 & 34.5 & 32.1 & 20.4 & 30.9 & 30.9 \\
\hline Row 5, Point 1 & 28.0 & 20.7 & 22.0 & 29.5 & 29.5 \\
\hline Row 5, Point 2 & 28.6 & 28.3 & 24.2 & 30.9 & 30.9 \\
\hline Row 5, Point 3 & 26.6 & 27.9 & 25.3 & 32.4 & 32.4 \\
\hline Row 5, Point 4 & 30.1 & 25.5 & 25.9 & 34.7 & 34.7 \\
\hline Row 5, Point 5 & 37.7 & 22.2 & 25.2 & 37.6 & 37.6 \\
\hline Row 5, Point 6 & 30.9 & 26.4 & 23.4 & 34.4 & 34.5 \\
\hline
\end{tabular}




\begin{tabular}{|l|c|c|c|c|c|}
\hline Full Power & Leviton & Leviton & Leviton & Leviton* & Lutron \\
\hline Dimmer & 75W A-Lamp & 65W R-Lamp & 20W CFL & 15W LED & 15W LED \\
\hline Lamp & 478 Watts & 363 Watts & 132 Watts & 84 Watts & 85 Watts \\
\hline Total Power & 31.5 & 30.1 & 22.0 & 32.2 & 32.3 \\
\hline Row 5, Point 7 & 33.7 & 23.4 & 21.0 & 31.0 & 31.0 \\
\hline Row 5, Point 8 & 33.5 & 19.0 & 19.2 & 29.6 & 29.8 \\
\hline Row 5, Point 9 & 30.84 & 27.50 & 24.80 & 34.13 & 34.18 \\
\hline Average-All Points &
\end{tabular}

* Dimmer switch later found to be not compatible with LED Module and replaced with a compatible dimmer switch. 
Table A.2. Vertical Illuminance Measurements (fc)

\begin{tabular}{|l|c|c|c|c|}
\hline \multicolumn{5}{|l|}{ Full Power } \\
\hline Lamp Type & A-Lamp & R-Lamp & CFL & LED \\
\hline Row 1, Point 1 & 20.40 & 19.30 & 12.60 & 19.50 \\
\hline Row 1, Point 2 & 12.40 & 8.21 & 15.80 & 16.90 \\
\hline Row 1, Point 3 & 9.90 & 5.31 & 19.70 & 16.80 \\
\hline Row 1, Point 4 & 11.90 & 9.80 & 19.70 & 17.10 \\
\hline Row 1, Point 5 & 18.30 & 19.30 & 16.30 & 20.30 \\
\hline Row 1, Point 6 & 10.70 & 9.58 & 17.90 & 17.60 \\
\hline Row 1, Point 7 & 11.30 & 5.16 & 20.10 & 17.60 \\
\hline Row 1, Point 8 & 12.30 & 9.87 & 19.70 & 16.90 \\
\hline Row 1, Point 9 & 19.50 & 19.70 & 13.70 & 20.20 \\
\hline Row 2, Point 1 & 12.80 & 12.60 & 12.90 & 12.50 \\
\hline Row 2, Point 2 & 11.00 & 8.95 & 15.00 & 13.50 \\
\hline Row 2, Point 3 & 9.78 & 6.40 & 17.10 & 13.40 \\
\hline Row 2, Point 4 & 10.70 & 11.60 & 17.50 & 13.70 \\
\hline Row 2, Point 5 & 12.80 & 14.20 & 16.70 & 13.10 \\
\hline Row 2, Point 6 & 10.30 & 9.56 & 17.00 & 14.10 \\
\hline Row 2, Point 7 & 9.84 & 6.49 & 17.90 & 13.40 \\
\hline Row 2, Point 8 & 11.60 & 11.80 & 16.50 & 13.50 \\
\hline Row 2, Point 9 & 14.30 & 14.50 & 13.00 & 12.30 \\
\hline Row 3, Point 1 & 8.22 & 7.34 & 11.80 & 12.90 \\
\hline Row 3, Point 2 & 9.59 & 8.36 & 13.50 & 13.10 \\
\hline Row 3, Point 3 & 8.42 & 7.64 & 14.70 & 12.40 \\
\hline Row 3, Point 4 & 9.29 & 9.41 & 15.60 & 13.40 \\
\hline Row 3, Point 5 & 9.50 & 10.00 & 16.20 & 14.30 \\
\hline Row 3, Point 6 & 9.39 & 8.91 & 16.30 & 12.80 \\
\hline Row 3, Point 7 & 8.19 & 7.56 & 15.90 & 11.60 \\
\hline Row 3, Point 8 & 9.80 & 8.56 & 14.20 & 11.60 \\
\hline Row 3, Point 9 & 9.64 & 8.41 & 12.70 & 11.30 \\
\hline Average-Row 1 & 14.08 & 11.80 & 17.28 & 18.10 \\
\hline Average-Row 2 & 11.46 & 10.68 & 15.96 & 13.28 \\
\hline Average-Row 3 & 9.12 & 8.47 & 14.54 & 12.60 \\
\hline Average-All Data & 11.55 & 10.32 & 15.93 & 14.66 \\
\hline
\end{tabular}


Table A.3. Horizontal Illuminance Measurements (fc) for Incandescent A-Lamp at Various Levels of Dimming

\begin{tabular}{|l|c|c|c|c|c|}
\hline \multicolumn{7}{|l|}{ Incandescent 75-Watt A-Lamp } \\
\hline Power (Watts) & $\mathbf{4 7 8}$ & $\mathbf{3 6 1}$ & $\mathbf{2 3 7}$ & $\mathbf{1 1 8}$ & $\mathbf{7 4}$ \\
\hline Power (\% of full) & $\mathbf{1 0 0 \%}$ & $\mathbf{7 6 \%}$ & $\mathbf{5 0 \%}$ & $\mathbf{2 5 \%}$ & $\mathbf{1 5 \%}^{\dagger}$ \\
\hline Row 1, Point 1 & 25.50 & 13.80 & 5.50 & 0.725 & 0.161 \\
\hline Row 1, Point 3 & 30.20 & 16.10 & 5.84 & 0.808 & 0.177 \\
\hline Row 1, Point 5 & 32.30 & 17.40 & 6.30 & 0.884 & 0.199 \\
\hline Row 3, Point 1 & 30.80 & 16.10 & 5.89 & 0.804 & 0.178 \\
\hline Row 3, Point 3 & 26.00 & 13.60 & 5.01 & 0.681 & 0.153 \\
\hline Row 3, Point 5 & 34.50 & 18.30 & 6.64 & 0.915 & 0.207 \\
\hline Row 5, Point 1 & 28.00 & 14.80 & 5.31 & 0.750 & 0.162 \\
\hline Row 5, Point 3 & 26.60 & 14.00 & 5.05 & 0.719 & 0.154 \\
\hline Row 5, Point 5 & 37.70 & 20.40 & 7.13 & 1.020 & 0.229 \\
\hline Average & 30.18 & 16.06 & 5.85 & 0.81 & 0.18 \\
\hline${ }^{\dagger}$ Minimum level of stable dimming achieved with dimmer. \\
\hline
\end{tabular}

Table A.4. Horizontal Illuminance Measurements (fc) for Incandescent R-Lamp at Various Levels of Dimming

\begin{tabular}{|l|c|c|c|c|c|}
\hline \multicolumn{7}{|l|}{ Incandescent 65-Watt R-Lamp } \\
\hline Power (Watts) & $\mathbf{3 6 3}$ & $\mathbf{2 7 3}$ & $\mathbf{1 8 4}$ & $\mathbf{9 1}$ & $\mathbf{5 9}$ \\
\hline Power (\% of full) & $\mathbf{1 0 0 \%}$ & $\mathbf{7 5 \%}$ & $\mathbf{5 1 \%}$ & $\mathbf{2 5 \%}$ & $\mathbf{1 6 \%}^{\dagger}$ \\
\hline Row 1, Point 1 & 18.40 & 9.39 & 3.18 & 3.450 & 0.640 \\
\hline Row 1, Point 3 & 29.80 & 15.00 & 5.17 & 0.564 & 0.102 \\
\hline Row 1, Point 5 & 23.60 & 11.90 & 4.13 & 0.450 & 0.083 \\
\hline Row 3, Point 1 & 40.10 & 15.10 & 5.22 & 0.567 & 0.102 \\
\hline Row 3, Point 3 & 25.30 & 12.70 & 4.37 & 0.480 & 0.089 \\
\hline Row 3, Point 5 & 32.70 & 16.50 & 5.70 & 0.625 & 0.114 \\
\hline Row 5, Point 1 & 20.70 & 10.30 & 3.54 & 0.384 & 0.070 \\
\hline Row 5, Point 3 & 27.90 & 14.00 & 4.83 & 0.520 & 0.097 \\
\hline Row 5, Point 5 & 22.20 & 11.10 & 3.87 & 0.425 & 0.078 \\
\hline Average & 26.74 & 12.89 & 4.45 & 0.83 & 0.15 \\
\hline${ }^{\dagger}$ Minimum level of stable dimming achieved with dimmer. \\
\hline
\end{tabular}


Table A.5. Horizontal Illuminance Measurements (fc) for Compact Fluorescent Lamp at Various Levels of Dimming

\begin{tabular}{|l|c|c|c|}
\hline \multicolumn{5}{|l|}{ Compact Fluorescent Lamp 20 Watt } \\
\hline Power (Watts) & $\mathbf{1 3 2}$ & $\mathbf{1 0 0}$ & $\mathbf{6 0}$ \\
\hline Power (\% of full) & $\mathbf{1 0 0 \%}$ & $\mathbf{7 6 \%}$ & $\mathbf{4 5 \%}^{\dagger}$ \\
\hline Row 1, Point 1 & 20.10 & 12.90 & 4.97 \\
\hline Row 1, Point 3 & 24.10 & 15.60 & 6.09 \\
\hline Row 1, Point 5 & 27.30 & 17.60 & 6.96 \\
\hline Row 3, Point 1 & 23.80 & 15.30 & 5.83 \\
\hline Row 3, Point 3 & 30.40 & 19.60 & 7.54 \\
\hline Row 3, Point 5 & 27.80 & 17.90 & 7.00 \\
\hline Row 5, Point 1 & 22.00 & 13.70 & 5.22 \\
\hline Row 5, Point 3 & 25.30 & 16.00 & 6.19 \\
\hline Row 5, Point 5 & 25.20 & 16.20 & 6.29 \\
\hline Average E & 25.11 & 16.09 & 6.23 \\
\hline $\begin{array}{l}{ }^{\dagger} \text { Minimum level of stable dimming achieved with } \\
\text { dimmer. }\end{array}$ \\
\hline
\end{tabular}

Table A.6. Horizontal Illuminance Measurements (fc) for LED at Various Levels of Dimming

\begin{tabular}{|l|c|c|c|c|c|}
\hline \multicolumn{7}{|l|}{ LED 15 Watt } \\
\hline Power (W) & $\mathbf{8 5}$ & $\mathbf{6 0}$ & $\mathbf{4 0}$ & $\mathbf{2 0}$ & $\mathbf{1 4}$ \\
\hline Power (\% of full) & $\mathbf{1 0 0 \%}$ & $\mathbf{7 1 \%}$ & $\mathbf{4 7 \%}$ & $\mathbf{2 4 \%}$ & $\mathbf{1 6 \%}^{\dagger}$ \\
\hline Row 1, Point 1 & 30.40 & 22.10 & 16.50 & 9.36 & 5.56 \\
\hline Row 1, Point 3 & 32.60 & 23.60 & 17.80 & 9.90 & 5.97 \\
\hline Row 1, Point 5 & 38.10 & 27.50 & 20.70 & 11.40 & 6.80 \\
\hline Row 3, Point 1 & 31.30 & 22.90 & 17.20 & 9.64 & 5.73 \\
\hline Row 3, Point 3 & 36.00 & 26.20 & 19.70 & 11.00 & 6.56 \\
\hline Row 3, Point 5 & 40.00 & 29.10 & 21.80 & 12.10 & 7.26 \\
\hline Row 5, Point 1 & 29.50 & 21.60 & 16.30 & 9.13 & 5.48 \\
\hline Row 5, Point 3 & 32.40 & 23.70 & 17.80 & 10.00 & 6.01 \\
\hline Row 5, Point 5 & 37.60 & 27.50 & 20.60 & 11.50 & 6.93 \\
\hline Average & 34.21 & 24.91 & 18.71 & 10.45 & 6.26 \\
\hline${ }^{\dagger}$ Minimum level of stable dimming achieved with dimmer. \\
\hline
\end{tabular}


Table A.7. Illuminance and Color Data Measurements for 75-Watt Incandescent A-Lamp (Illuminance [fc], Color Coordinates [u’, v’], and Resulting Correlated Color Temperature)

\begin{tabular}{|c|c|c|c|c|c|c|c|c|c|c|c|c|c|}
\hline \multirow{2}{*}{\multicolumn{2}{|c|}{$\begin{array}{l}\text { 100-Watt } \\
\text { A-Lamp }\end{array}$}} & \multicolumn{4}{|c|}{ Column 1} & \multicolumn{4}{|c|}{ Column 3} & \multicolumn{4}{|c|}{ Column 5} \\
\hline & & fc & u' & v' & CCT & fc & $\mathrm{u}^{\prime}$ & v' & CCT & fc & $\mathrm{u}^{\prime}$ & v' & CCT \\
\hline \multirow{3}{*}{$100 \%$} & Row 1 & 289 & 0.474 & 0.404 & 2464 & 286 & 0.473 & 0.403 & 2469 & 312 & 0.476 & 0.403 & 2432 \\
\hline & Row 3 & 289 & 0.471 & 0.404 & 2501 & 243 & 0.47 & 0.403 & 2506 & 317 & 0.473 & 0.403 & 2469 \\
\hline & Row 5 & 270 & 0.474 & 0.404 & 2464 & 251 & 0.471 & 0.403 & 2494 & 357 & 0.481 & 0.403 & 2374 \\
\hline \multirow{3}{*}{$75 \%$} & Row 1 & 136 & 0.487 & 0.404 & 2314 & 152 & 0.487 & 0.405 & 2321 & 166 & 0.49 & 0.405 & 2289 \\
\hline & Row 3 & 152 & 0.486 & 0.405 & 2332 & 128 & 0.485 & 0.404 & 2336 & 171 & 0.487 & 0.405 & 2321 \\
\hline & Row 5 & 143 & 0.487 & 0.407 & 2335 & 132 & 0.485 & 0.405 & 2343 & 189 & 0.495 & 0.404 & 2229 \\
\hline \multirow{3}{*}{$50 \%$} & Row 1 & 48.4 & 0.51 & 0.404 & 2085 & 53.7 & 0.509 & 0.404 & 2094 & 59.2 & 0.512 & 0.403 & 2060 \\
\hline & Row 3 & 54.4 & 0.509 & 0.405 & 2100 & 45.5 & 0.507 & 0.404 & 2112 & 60.5 & 0.509 & 0.404 & 2094 \\
\hline & Row 5 & 51.9 & 0.509 & 0.407 & 2114 & 47.3 & 0.508 & 0.404 & 2103 & 71.2 & 0.513 & 0.409 & 2090 \\
\hline \multirow{3}{*}{$25 \%$} & Row 1 & 7.4 & 0.543 & 0.397 & 1780 & 8.3 & 0.543 & 0.399 & 1791 & 9.1 & 0.545 & 0.398 & 1771 \\
\hline & Row 3 & 8.3 & 0.542 & 0.399 & 1798 & 7 & 0.541 & 0.399 & 1805 & 9.3 & 0.542 & 0.399 & 1798 \\
\hline & Row 5 & 7.7 & 0.543 & 0.401 & 1803 & 7.2 & 0.541 & 0.399 & 1805 & 11 & 0.546 & 0.401 & 1782 \\
\hline
\end{tabular}

Table A.8. Illuminance and Color Data Measurements for 65-Watt Incandescent R-Lamp (Illuminance [fc], Color Coordinates [u', v'], and Resulting Correlated Color Temperature)

\begin{tabular}{|c|c|c|c|c|c|c|c|c|c|c|c|c|c|}
\hline \multirow{2}{*}{\multicolumn{2}{|c|}{$\begin{array}{l}\text { 65-Watt } \\
\text { R-Lamp }\end{array}$}} & \multicolumn{4}{|c|}{ Column 1} & \multicolumn{4}{|c|}{ Column 3} & \multicolumn{4}{|c|}{ Column 5} \\
\hline & & fc & $\mathrm{u}^{\prime}$ & v' & CCT & fc & u’ & $\mathrm{v}^{\prime}$ & CCT & fc & $\mathrm{u}^{\prime}$ & $\mathrm{v}^{\prime}$ & CCT \\
\hline \multirow{3}{*}{$100 \%$} & Row 1 & 177 & 0.486 & 0.404 & 2325 & 278 & 0.487 & 0.405 & 2321 & 221 & 0.487 & 0.404 & 2314 \\
\hline & Row 3 & 307 & 0.486 & 0.406 & 2339 & 231 & 0.487 & 0.404 & 2314 & 284 & 0.487 & 0.404 & 2314 \\
\hline & Row 5 & 200 & 0.488 & 0.404 & 2303 & 264 & 0.487 & 0.406 & 2328 & 216 & 0.486 & 0.405 & 2332 \\
\hline \multirow{3}{*}{$75 \%$} & Row 1 & 89 & 0.498 & 0.406 & 2213 & 142 & 0.501 & 0.405 & 2176 & 114 & 0.5 & 0.405 & 2186 \\
\hline & Row 3 & 144 & 0.5 & 0.406 & 2193 & 117 & 0.501 & 0.404 & 2169 & 156 & 0.501 & 0.407 & 2190 \\
\hline & Row 5 & 100 & 0.5 & 0.406 & 2193 & 133 & 0.502 & 0.406 & 2173 & 110 & 0.498 & 0.409 & 2233 \\
\hline \multirow{3}{*}{$50 \%$} & Row 1 & 31.1 & 0.522 & 0.404 & 1981 & 48.7 & 0.522 & 0.404 & 1981 & 40.1 & 0.521 & 0.405 & 1995 \\
\hline & Row 3 & 49.5 & 0.522 & 0.404 & 1981 & 40 & 0.523 & 0.403 & 1966 & 54 & 0.522 & 0.405 & 1987 \\
\hline & Row 5 & 34.2 & 0.523 & 0.404 & 1973 & 45.9 & 0.524 & 0.404 & 1964 & 37.6 & 0.521 & 0.406 & 2002 \\
\hline \multirow{3}{*}{$25 \%$} & Row 1 & 3.3 & 0.561 & 0.392 & 1635 & 5.3 & 0.562 & 0.393 & 1634 & 4.4 & 0.561 & 0.394 & 1645 \\
\hline & Row 3 & 5.4 & 0.563 & 0.393 & 1628 & 4.4 & 0.562 & 0.392 & 1629 & 6 & 0.56 & 0.395 & 1657 \\
\hline & Row 5 & 3.7 & 0.562 & 0.394 & 1639 & 5 & 0.561 & 0.394 & 1645 & 4.2 & 0.559 & 0.397 & 1674 \\
\hline
\end{tabular}


Table A.9. Illuminance and Color Data Measurements for 20-Watt Compact Fluorescent Lamp

(Illuminance [fc], Color Coordinates [u', v'], and Resulting Correlated Color Temperature)

\begin{tabular}{|c|c|c|c|c|c|c|c|c|c|c|c|c|c|}
\hline \multirow{2}{*}{\multicolumn{2}{|c|}{$\begin{array}{l}20 \text { Watt } \\
\text { CFL }\end{array}$}} & \multicolumn{4}{|c|}{ Column 1} & \multicolumn{4}{|c|}{ Column 3} & \multicolumn{4}{|c|}{ Column 5} \\
\hline & & fc & $\mathrm{u}^{\prime}$ & $\mathrm{v}^{\prime}$ & CCT & fc & $\mathrm{u}^{\prime}$ & $\mathrm{v}^{\prime}$ & CCT & fc & $\mathrm{u}^{\prime}$ & $\mathrm{v}^{\prime}$ & CCT \\
\hline \multirow{3}{*}{$100 \%$} & Row 1 & 185 & 0.484 & 0.415 & 2427 & 223 & 0.483 & 0.471 & 2825 & 247 & 0.483 & 0.416 & 2446 \\
\hline & Row 3 & 227 & 0.484 & 0.415 & 2427 & 285 & 0.481 & 0.416 & 2469 & 256 & 0.482 & 0.416 & 2457 \\
\hline & Row 5 & 202 & 0.485 & 0.414 & 2408 & 231 & 0.484 & 0.414 & 2420 & 229 & 0.484 & 0.416 & 2434 \\
\hline \multirow{3}{*}{$75 \%$} & Row 1 & 113 & 0.486 & 0.412 & 2383 & 141 & 0.486 & 0.412 & 2383 & 159 & 0.485 & 0.411 & 2387 \\
\hline & Row 3 & 138 & 0.484 & 0.411 & 2398 & 179 & 0.485 & 0.411 & 2387 & 163 & 0.485 & 0.41 & 2379 \\
\hline & Row 5 & 120 & 0.486 & 0.411 & 2375 & 142 & 0.486 & 0.409 & 2361 & 143 & 0.487 & 0.412 & 2371 \\
\hline \multirow{3}{*}{$50 \%$} & Row 1 & 42.5 & 0.48 & 0.404 & 2393 & 52.7 & 0.481 & 0.406 & 2396 & 62.2 & 0.479 & 0.404 & 2404 \\
\hline & Row 3 & 52.5 & 0.479 & 0.404 & 2404 & 69.6 & 0.479 & 0.405 & 2412 & 65.1 & 0.479 & 0.404 & 2404 \\
\hline & Row 5 & 49.1 & 0.481 & 0.403 & 2374 & 57.8 & 0.48 & 0.402 & 2378 & 58.1 & 0.481 & 0.405 & 2389 \\
\hline
\end{tabular}

Table A.10. Illuminance and Color Data Measurements for 15-Watt LED

(Illuminance [fc], Color Coordinates [u', v'], and Resulting Correlated Color Temperature)

\begin{tabular}{|c|c|c|c|c|c|c|c|c|c|c|c|c|c|}
\hline \multirow{2}{*}{\multicolumn{2}{|c|}{$\begin{array}{l}\text { 15-Watt } \\
\text { LED }\end{array}$}} & \multicolumn{4}{|c|}{ Column 1} & \multicolumn{4}{|c|}{ Column 3} & \multicolumn{4}{|c|}{ Column 5} \\
\hline & & fc & $u^{\prime}$ & $v^{\prime}$ & CCT & fc & $u^{\prime}$ & $\mathrm{v}^{\prime}$ & CCT & fc & $u^{\prime}$ & $v^{\prime}$ & CCT \\
\hline \multirow{3}{*}{$100 \%$} & Row 1 & 282 & 0.441 & 0.406 & 2948 & 300 & 0.442 & 0.407 & 2940 & 349 & 0.442 & 0.406 & 2932 \\
\hline & Row 3 & 287 & 0.442 & 0.406 & 2932 & 328 & 0.443 & 0.406 & 2916 & 366 & 0.442 & 0.406 & 2932 \\
\hline & Row 5 & 274 & 0.443 & 0.408 & 2932 & 298 & 0.444 & 0.407 & 2908 & 345 & 0.443 & 0.407 & 2924 \\
\hline \multirow{3}{*}{$75 \%$} & Row 1 & 204 & 0.44 & 0.407 & 2973 & 216 & 0.44 & 0.407 & 2973 & 250 & 0.44 & 0.407 & 2973 \\
\hline & Row 3 & 210 & 0.441 & 0.407 & 2956 & 239 & 0.442 & 0.408 & 2948 & 265 & 0.441 & 0.407 & 2956 \\
\hline & Row 5 & 200 & 0.442 & 0.409 & 2956 & 218 & 0.443 & 0.408 & 2932 & 254 & 0.442 & 0.408 & 2948 \\
\hline \multirow{3}{*}{$50 \%$} & Row 1 & 155 & 0.44 & 0.408 & 2981 & 163 & 0.44 & 0.408 & 2981 & 190 & 0.44 & 0.408 & 2981 \\
\hline & Row 3 & 158 & 0.441 & 0.408 & 2964 & 181 & 0.442 & 0.408 & 2948 & 201 & 0.441 & 0.407 & 2956 \\
\hline & Row 5 & 151 & 0.442 & 0.409 & 2956 & 164 & 0.443 & 0.408 & 2932 & 191 & 0.441 & 0.408 & 2964 \\
\hline \multirow{3}{*}{$25 \%$} & Row 1 & 87.1 & 0.439 & 0.408 & 2997 & 92.7 & 0.44 & 0.408 & 2981 & 0.41 & 0.44 & 0.408 & 2981 \\
\hline & Row 3 & 89.9 & 0.44 & 0.408 & 2981 & 102 & 0.441 & 0.441 & 3213 & 0.41 & 0.441 & 0.408 & 2964 \\
\hline & Row 5 & 85.8 & 0.442 & 0.41 & 2964 & 93.1 & 0.442 & 0.442 & 3204 & 0.41 & 0.441 & 0.409 & 2972 \\
\hline
\end{tabular}


Table A.11. Correlated Color Temperature Shift with Dimming

\begin{tabular}{|l|c|c|c|c|}
\hline Lamp Type & \multicolumn{4}{|c|}{ Average CCT } \\
\hline \multicolumn{1}{|c|}{ Relative Input Power } & $\mathbf{1 0 0 \%}$ & $\mathbf{7 5 \%}$ & $\mathbf{5 0 \%}$ & $\mathbf{2 5 \%}$ \\
\hline A-Lamp & 2464 & 2313 & 2095 & 1793 \\
\hline R-Lamp & 2321 & 2192 & 1981 & 1643 \\
\hline CFL & 2479 & 2380 & 2395 & \\
\hline LED & 2929 & 2957 & 2963 & 3029 \\
\hline
\end{tabular}




\section{Appendix B. Power Quality Measurements}


General Electric, 90107, Basic 75, A-19, rated 1190 lumens, 750 hour life

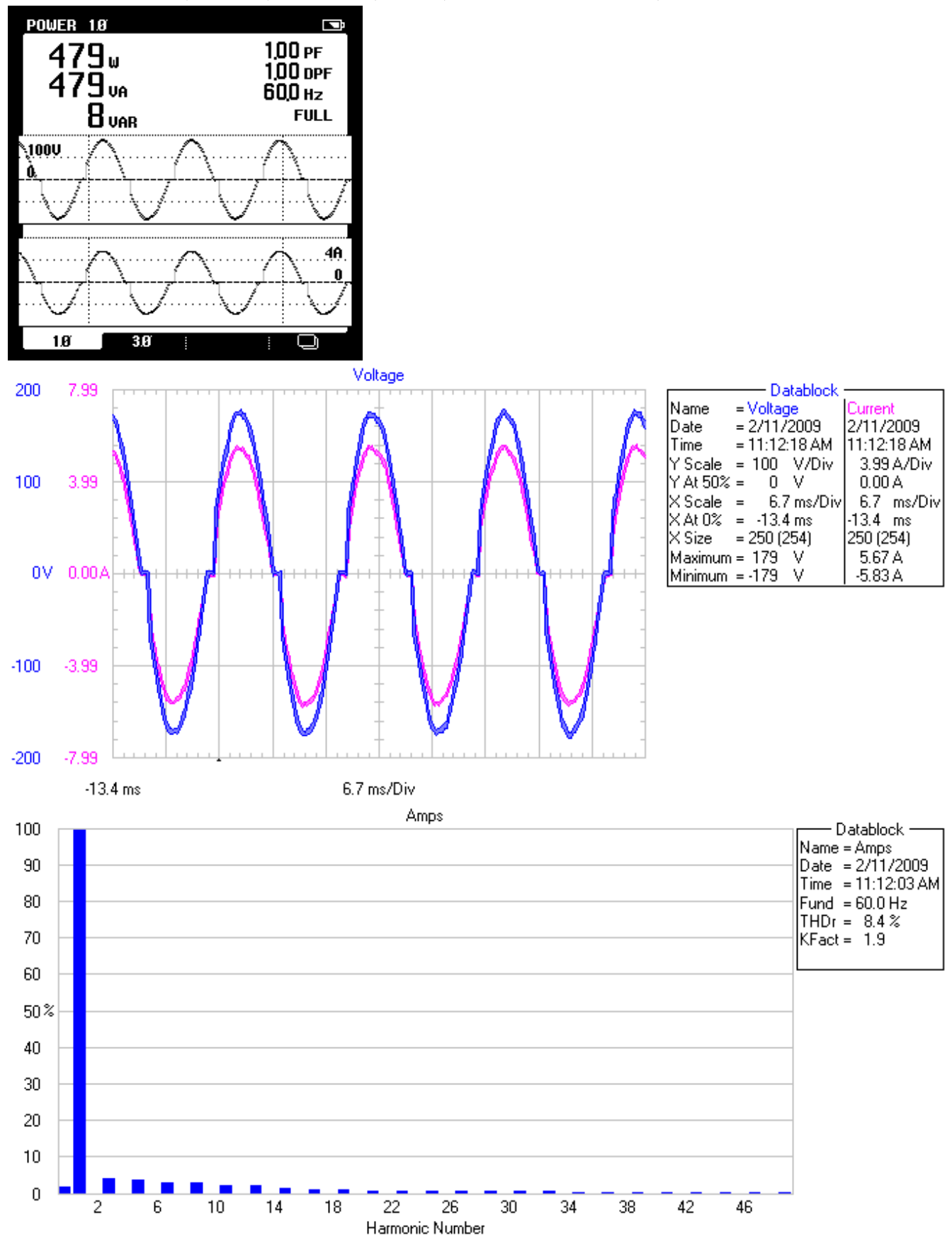

Switch: Lutron model 81000, 1000-Watt

Test Instrument: Fluke Model 43B Power Quality Analyzer

Figure B.1. Power Quality Measurements for 75-Watt Incandescent A-Lamp at Full Power 
General Electric, 90107, Basic 75, A-19, rated 1190 lumens, 750 hour life
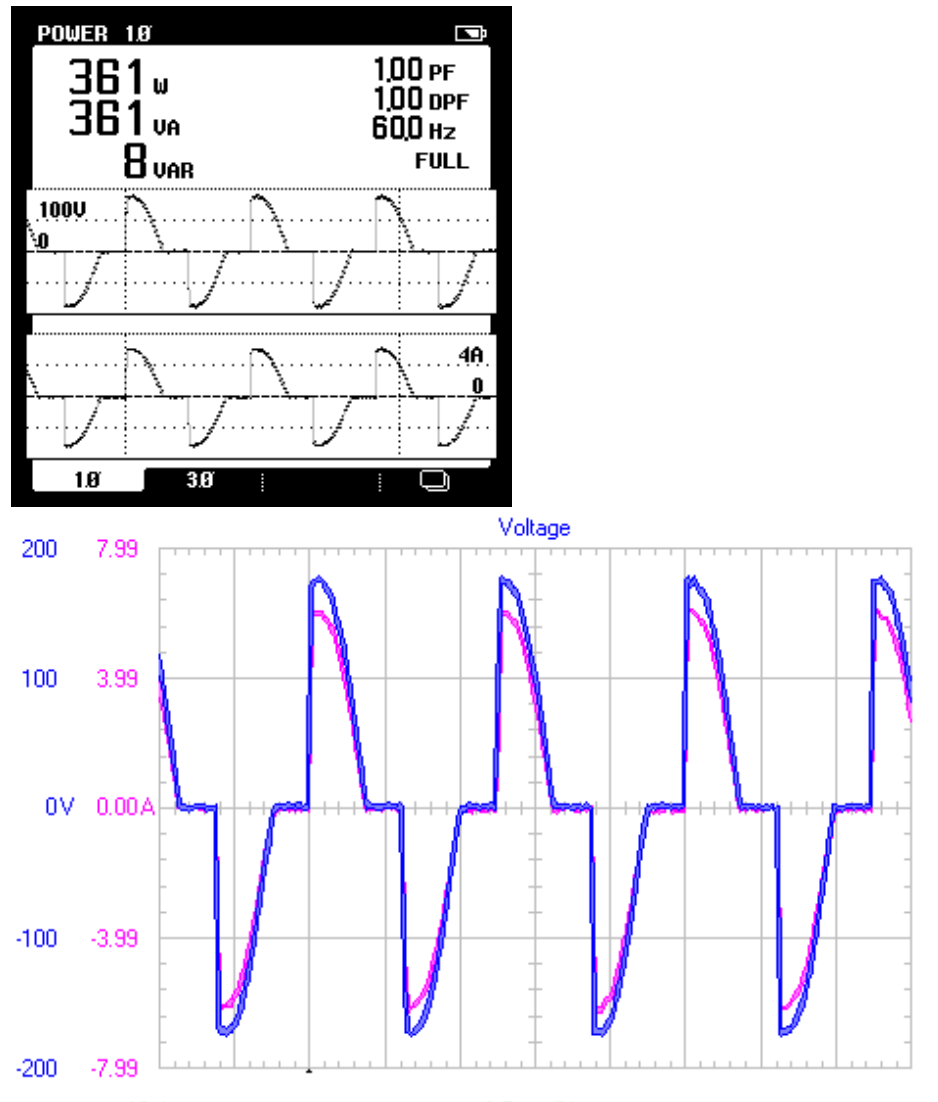

\begin{tabular}{|ll|l|}
\hline Name & $=$ Voltage & Current \\
\cline { 3 - 3 } Date & $=2 / 11 / 2009$ & $2 / 11 / 2009$ \\
Time & $=11: 24: 55 \mathrm{AM}$ & $11: 24: 55 \mathrm{AM}$ \\
Y Scale & $=100 \mathrm{~V} /$ Div & $3.99 \mathrm{~A} / \mathrm{Div}$ \\
Y At 50\% & $=0 \mathrm{~V}$ & $0.00 \mathrm{~A}$ \\
$\times$ Scale & $=6.7 \mathrm{~ms} /$ Div & $6.7 \mathrm{~ms} / \mathrm{Div}$ \\
XAt 0\% & $=-13.4 \mathrm{~ms}$ & $-13.4 \mathrm{~ms}$ \\
XSize & $=250[254)$ & $250[254]$ \\
Maximum & $=179 \mathrm{~V}$ & $6.15 \mathrm{~A}$ \\
Minimum & $=-177 \mathrm{~V}$ & $-6.31 \mathrm{~A}$ \\
\hline
\end{tabular}

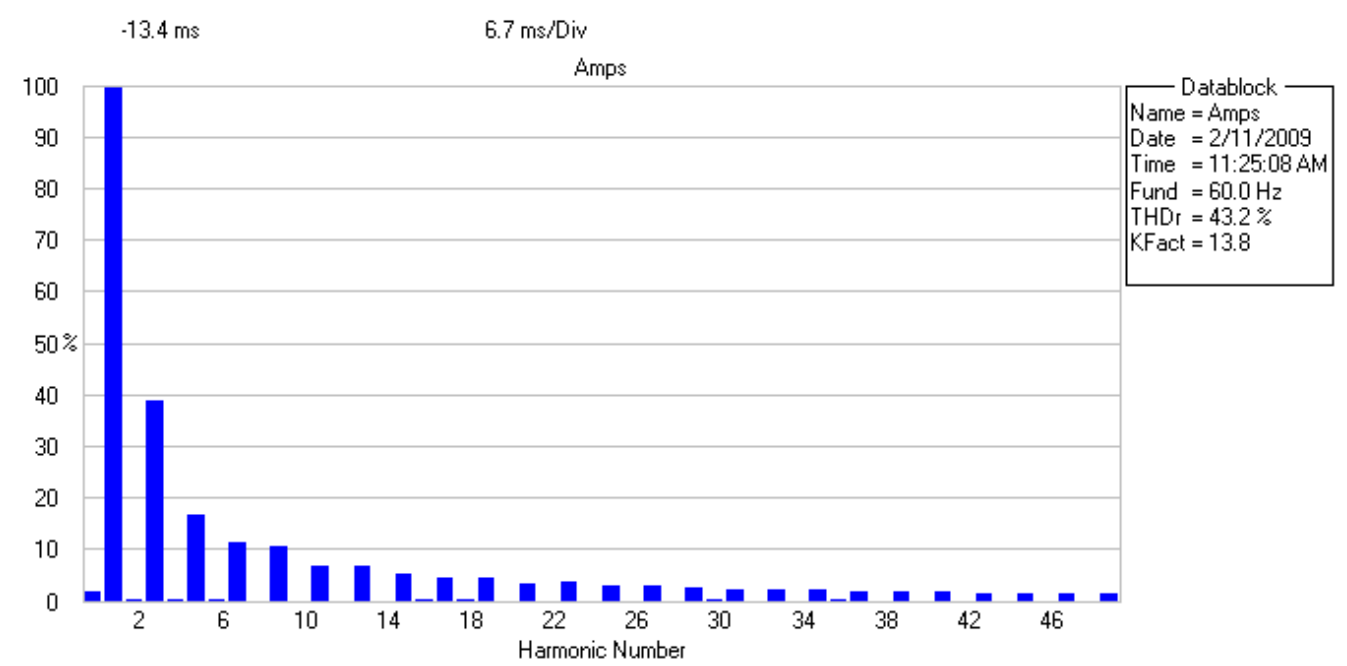

Switch: Lutron model 81000, 1000-Watt

Test Instrument: Fluke Model 43B Power Quality Analyzer

Figure B.2. Power Quality Measurements for 75-Watt Incandescent A-Lamp at 75\% Power 
General Electric, 90107, Basic 75, A-19, rated 1190 lumens, 750 hour life

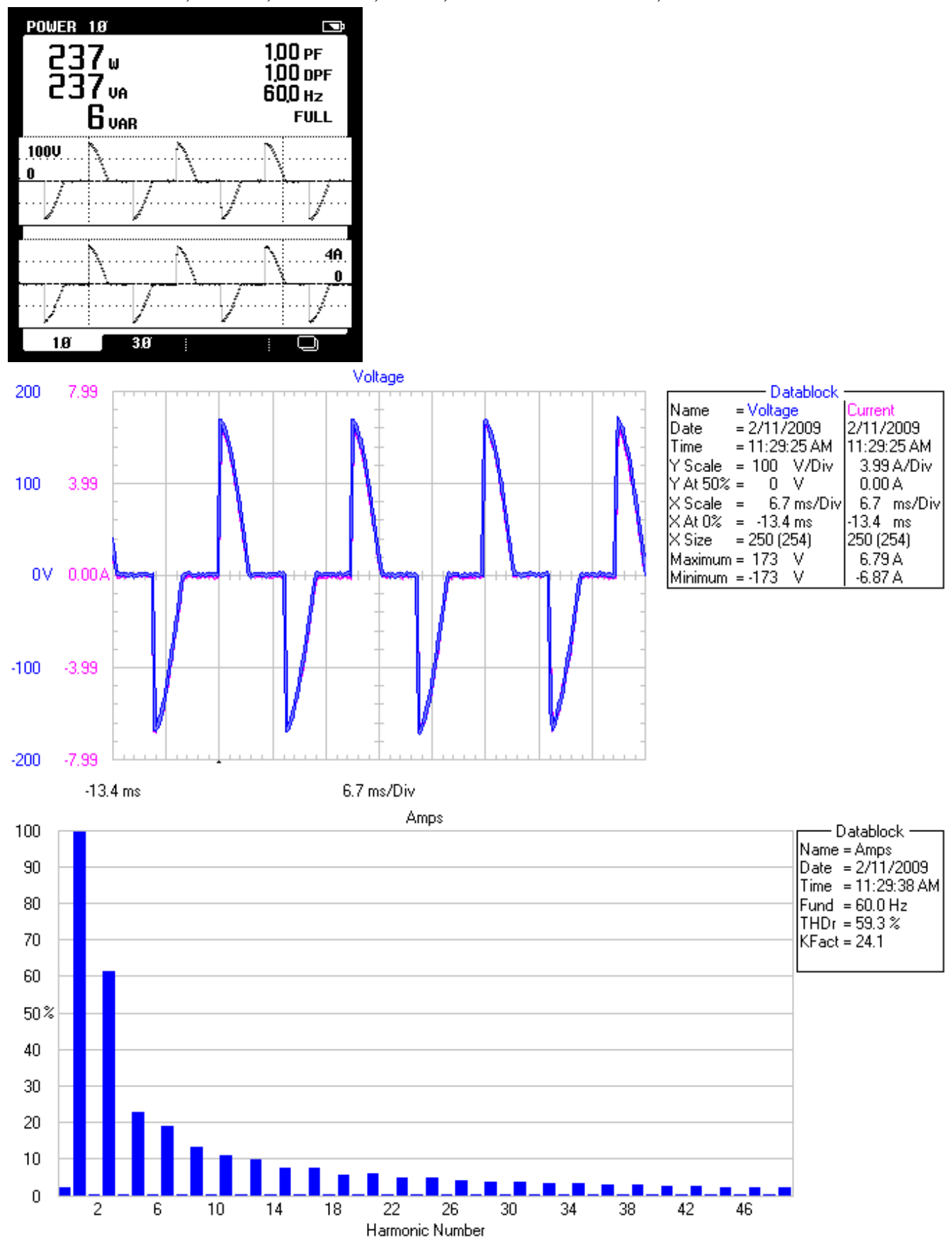

Switch: Lutron model 81000, 1000-Watt

Test Instrument: Fluke Model 43B Power Quality Analyzer

Figure B.3. Power Quality Measurements for 75-Watt Incandescent A-Lamp at 50\% Power 
General Electric, 90107, Basic 75, A-19, rated 1190 lumens, 750 hour life

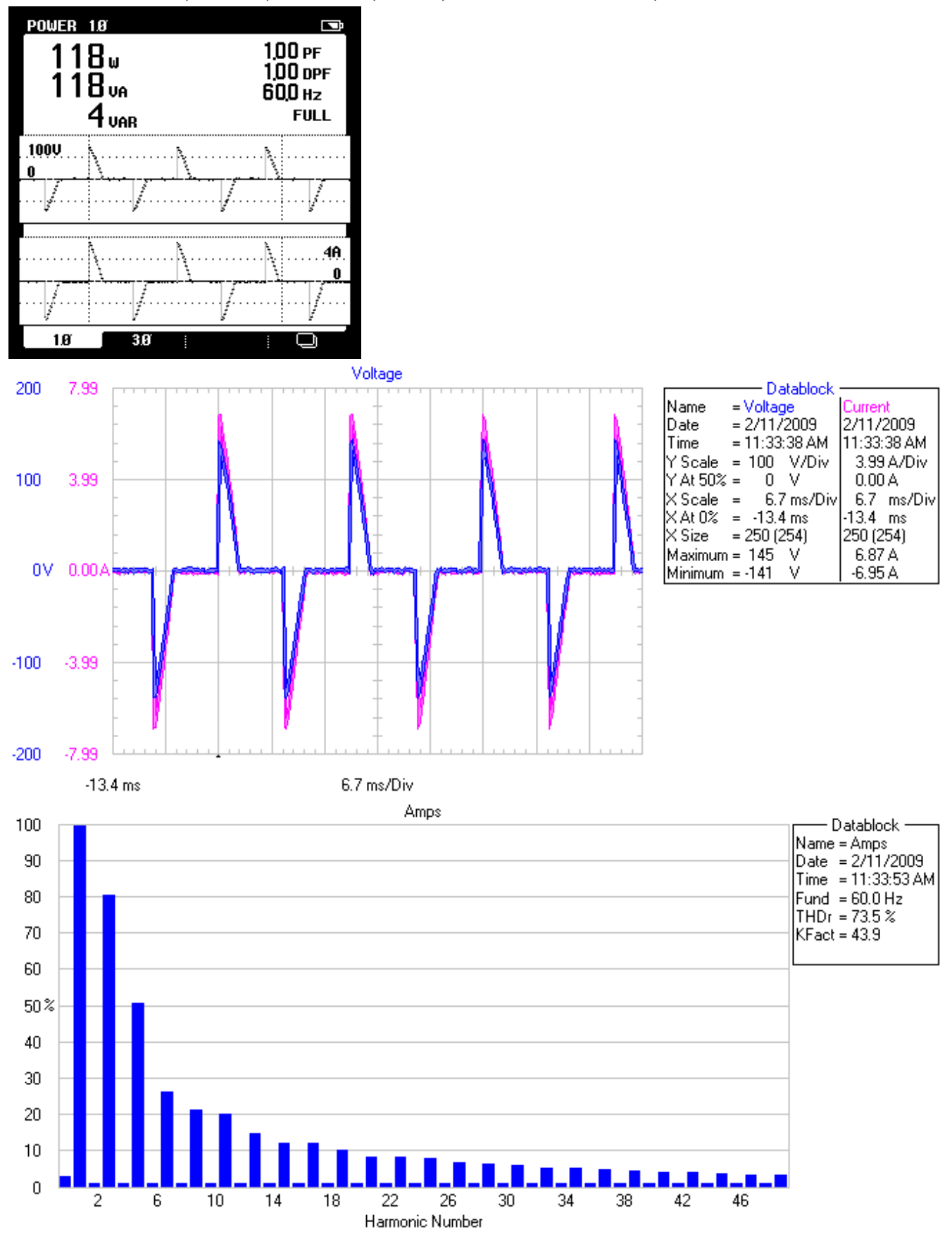

Switch: Lutron model 81000, 1000-Watt

Test Instrument: Fluke Model 43B Power Quality Analyzer

Figure B.4. Power Quality Measurements for 75-Watt Incandescent A-Lamp at 25\% Power 
General Electric, 90107, Basic 75, A-19, rated 1190 lumens, 750 hour life

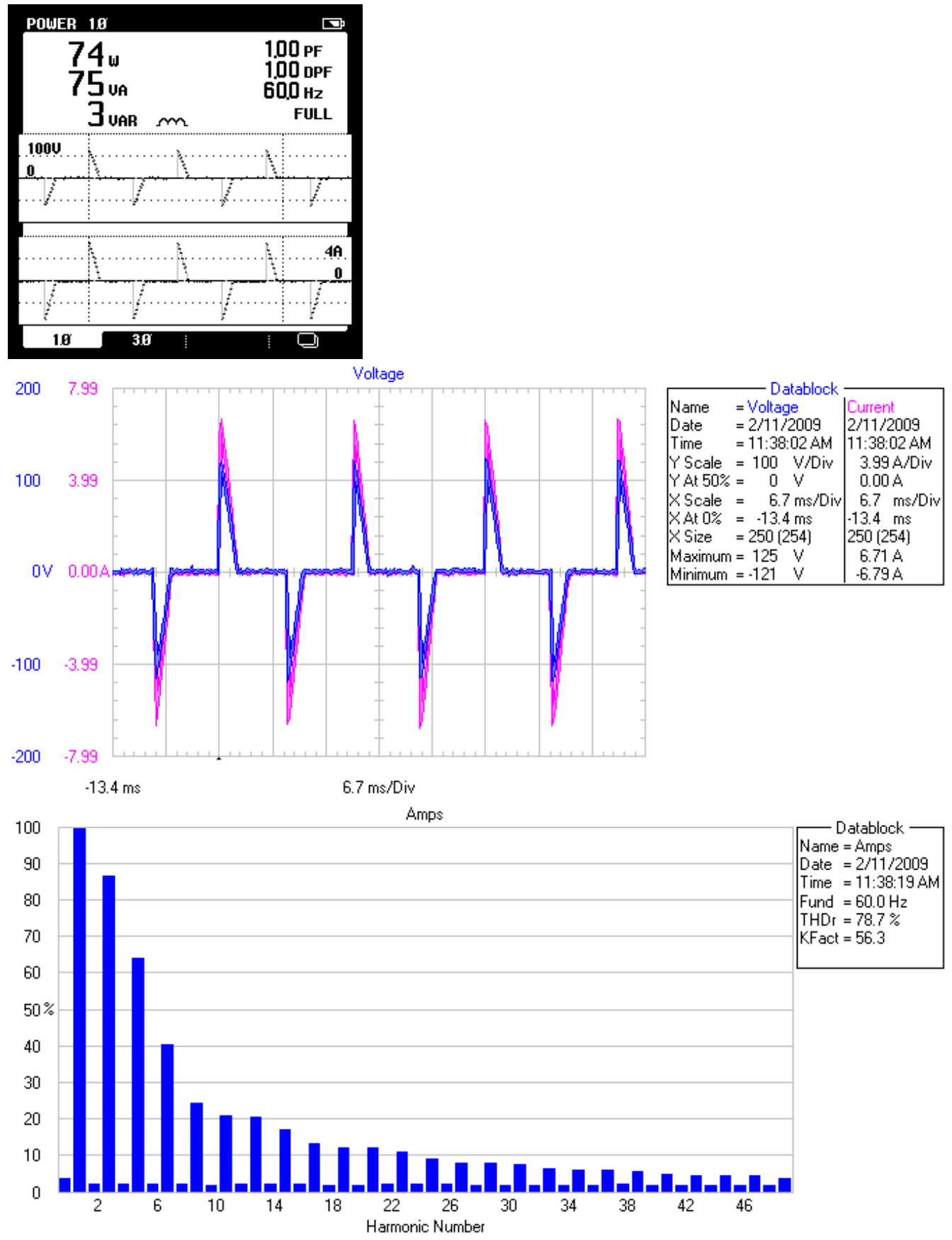

Switch: Lutron model 81000, 1000-Watt

Test Instrument: Fluke Model 43B Power Quality Analyzer

Figure B.5. Power Quality Measurements for 75-Watt Incandescent A-Lamp at Minimum Power 
General Electric , 14263, Watt-Miser, R-30, rated 755 lumens, 2000 hour life, 130-volt
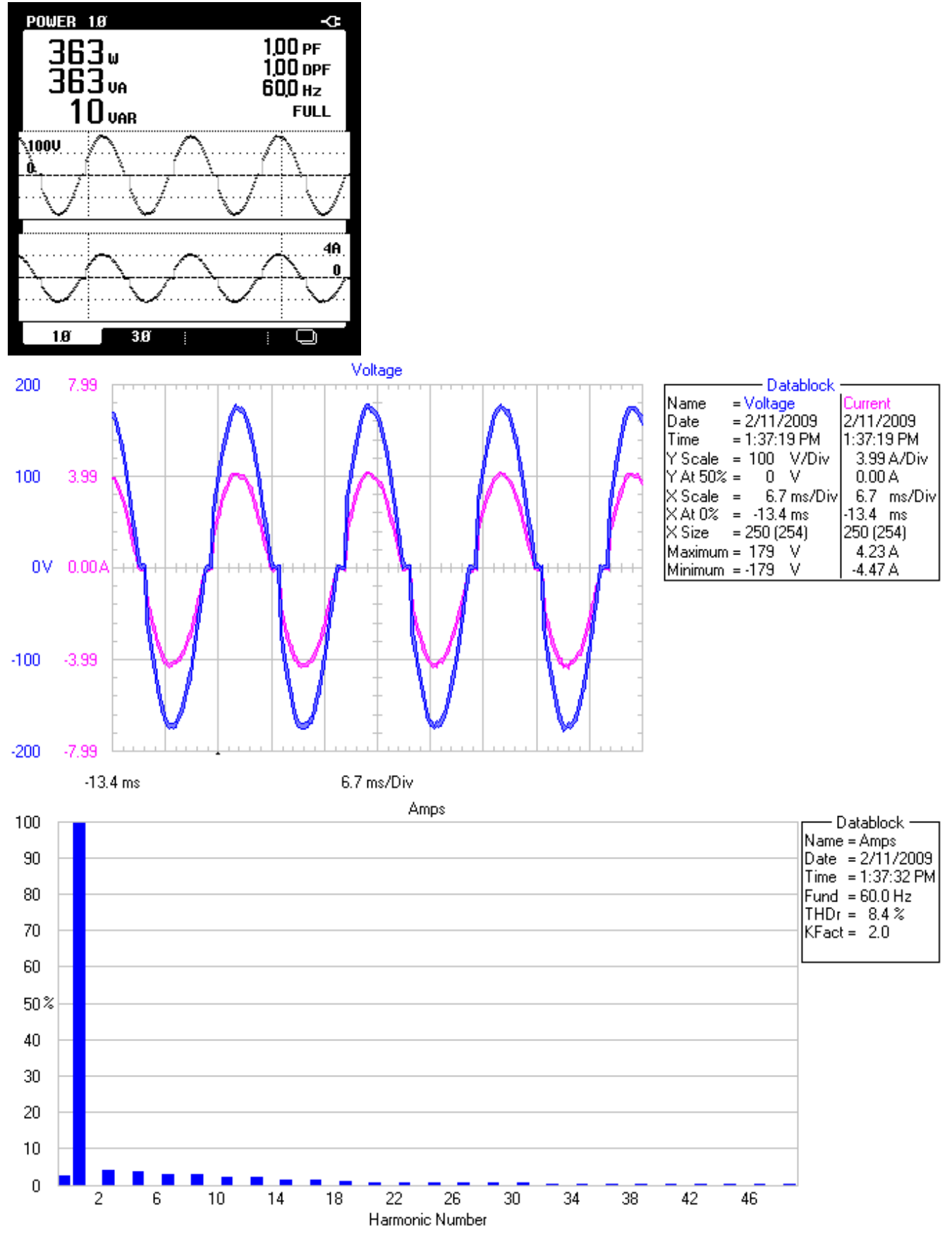

Switch: Lutron model 81000, 1000-Watt

Test Instrument: Fluke Model 43B Power Quality Analyzer

Figure B.6. Power Quality Measurements for 65-Watt Incandescent R-Lamp at Full Power 
General Electric , 14263, Watt-Miser, R-30, rated 755 lumens, 2000 hour life, 130-volt
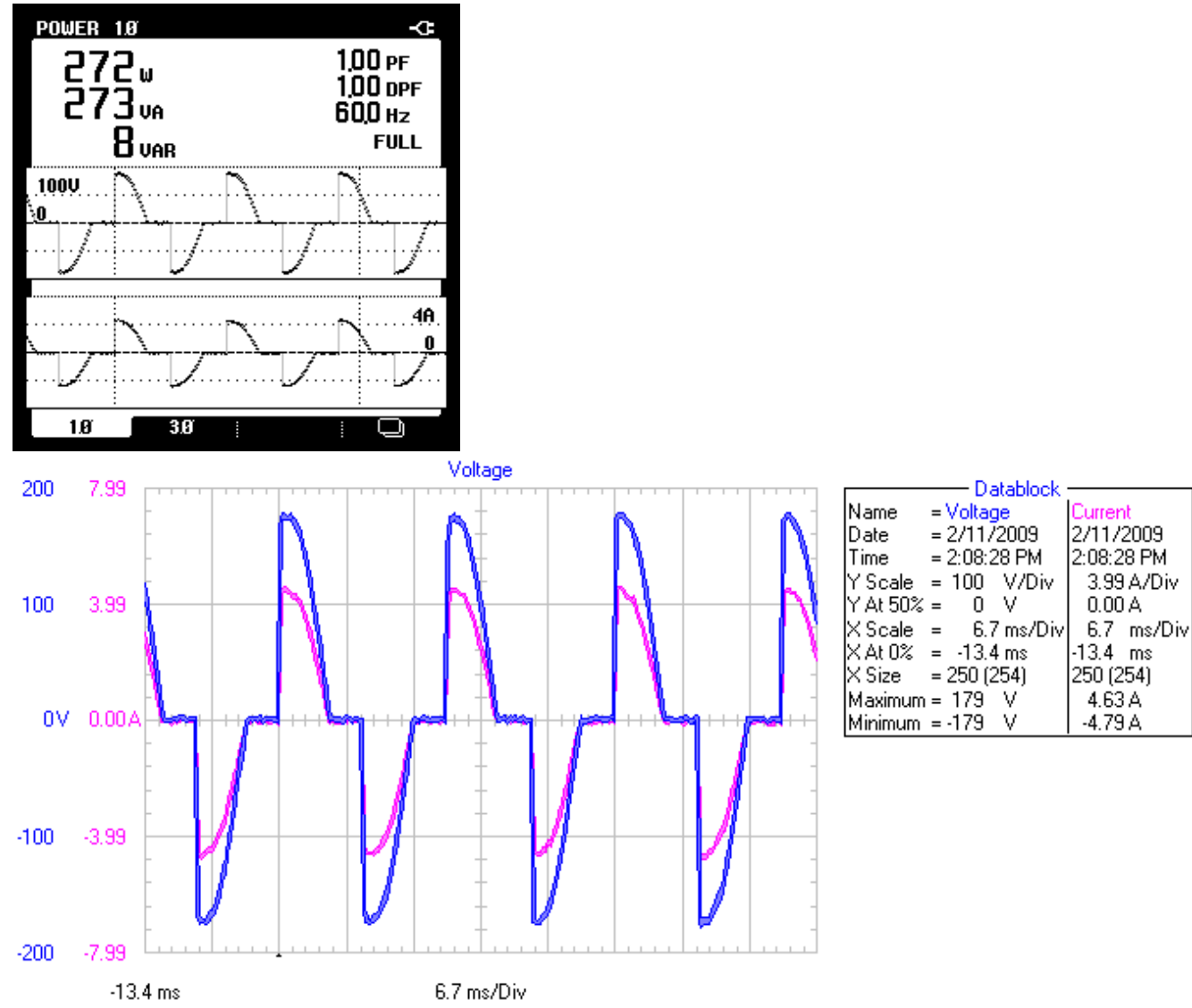

$6.7 \mathrm{~ms} / \mathrm{Div}$

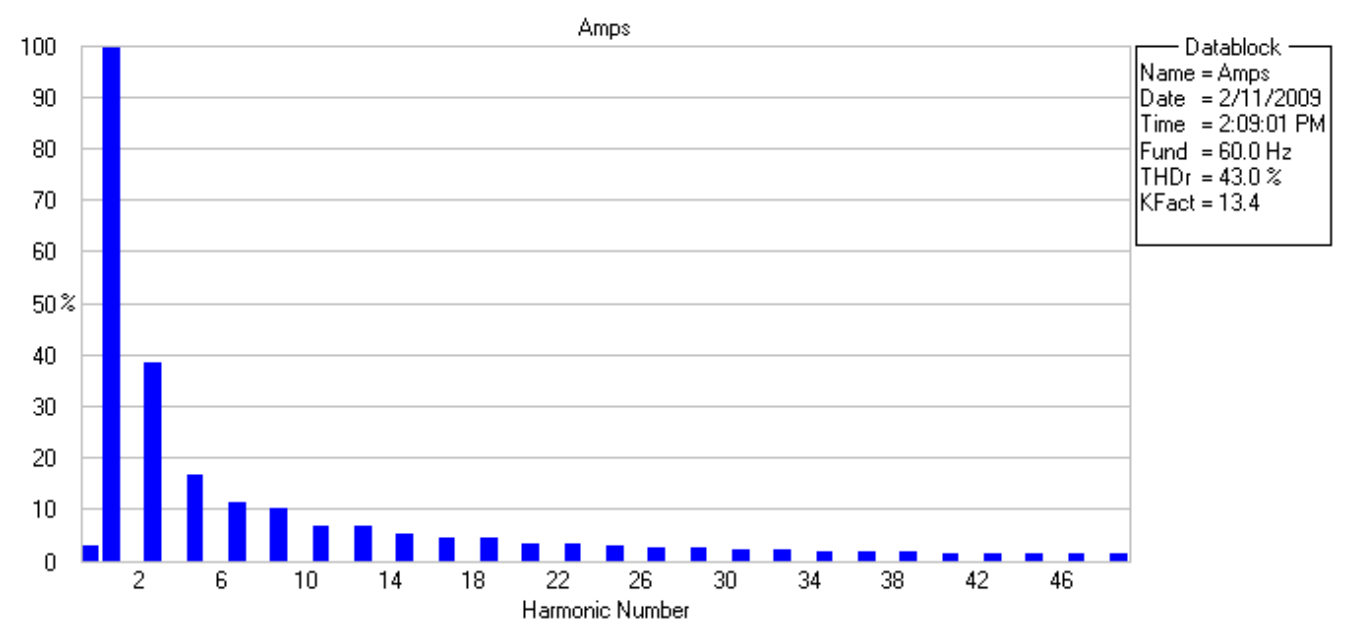

Switch: Lutron model 81000, 1000-Watt

Test Instrument: Fluke Model 43B Power Quality Analyzer

Figure B.7. Power Quality Measurements for 65-Watt Incandescent R-Lamp at 75\% Power 
General Electric , 14263, Watt-Miser, R-30, rated 755 lumens, 2000 hour life, 130-volt
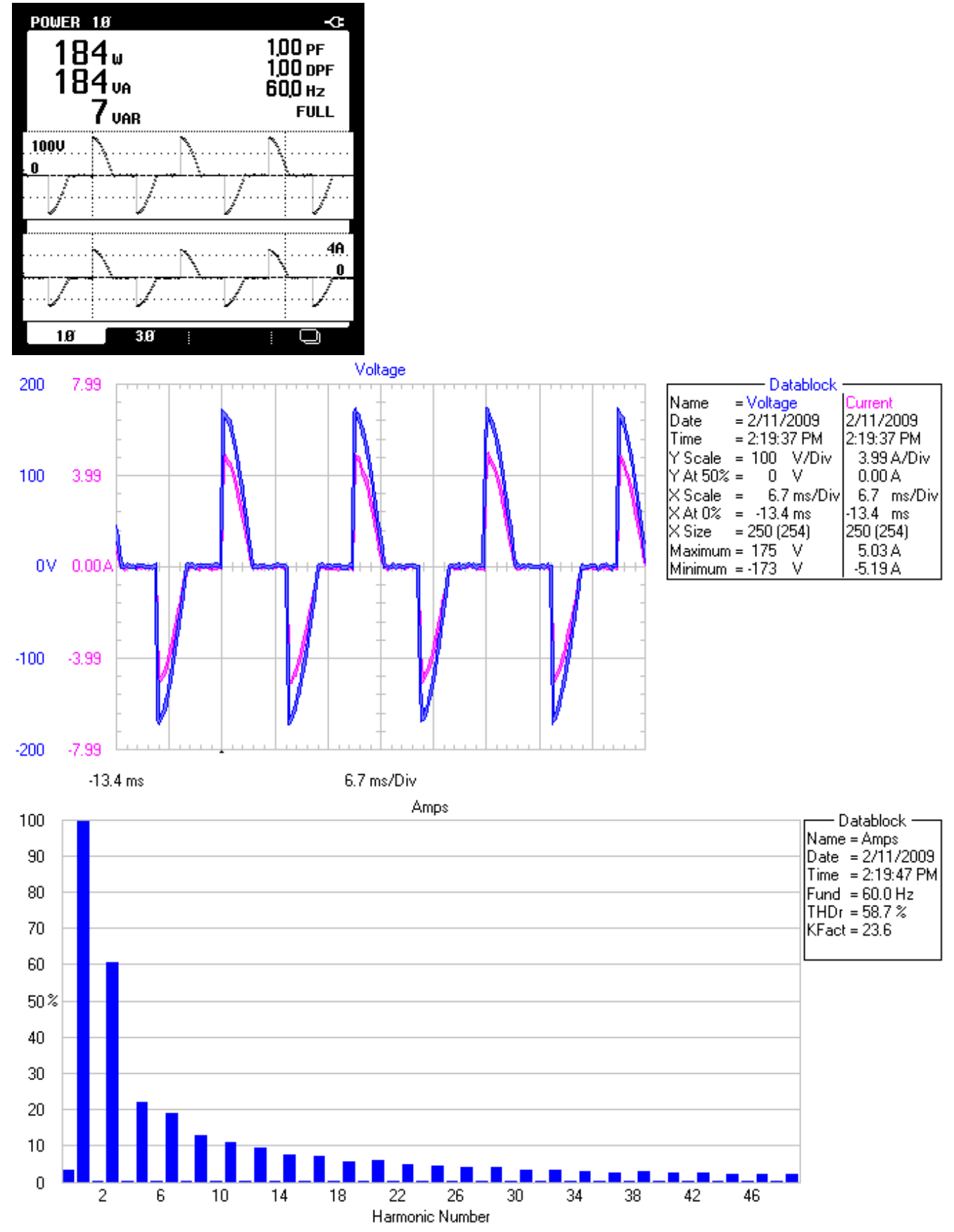

Switch: Lutron model 81000, 1000-Watt

Test Instrument: Fluke Model 43B Power Quality Analyzer

Figure B.8. Power Quality Measurements for 65-Watt Incandescent R-Lamp at 50\% Power 
General Electric , 14263, Watt-Miser, R-30, rated 755 lumens, 2000 hour life, 130-volt

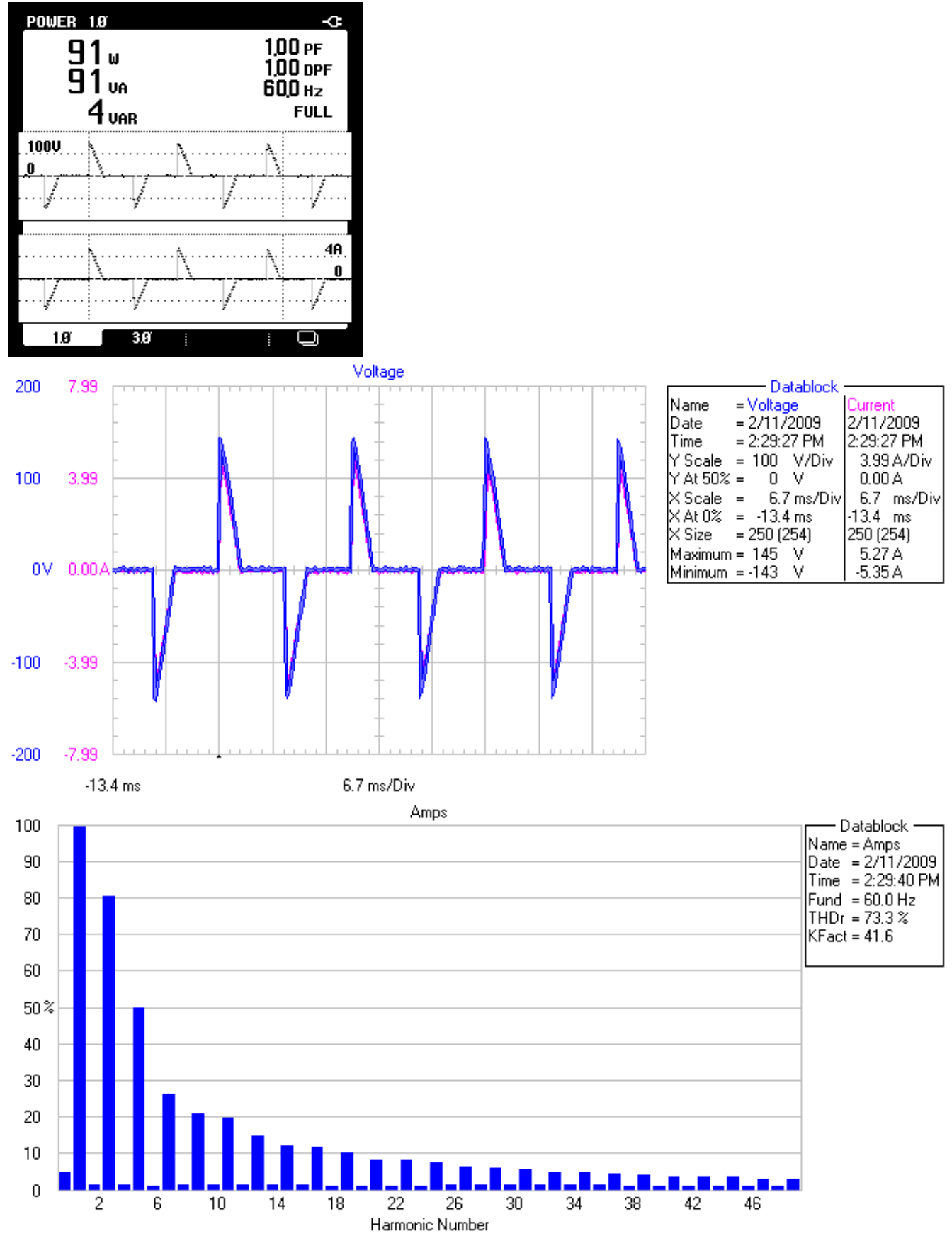

Switch: Lutron model 81000, 1000-Watt

Test Instrument: Fluke Model 43B Power Quality Analyzer

Figure B.9. Power Quality Measurements for 65-Watt Incandescent R-Lamp at 25\% Power 
General Electric , 14263, Watt-Miser, R-30, rated 755 lumens, 2000 hour life, 130-volt

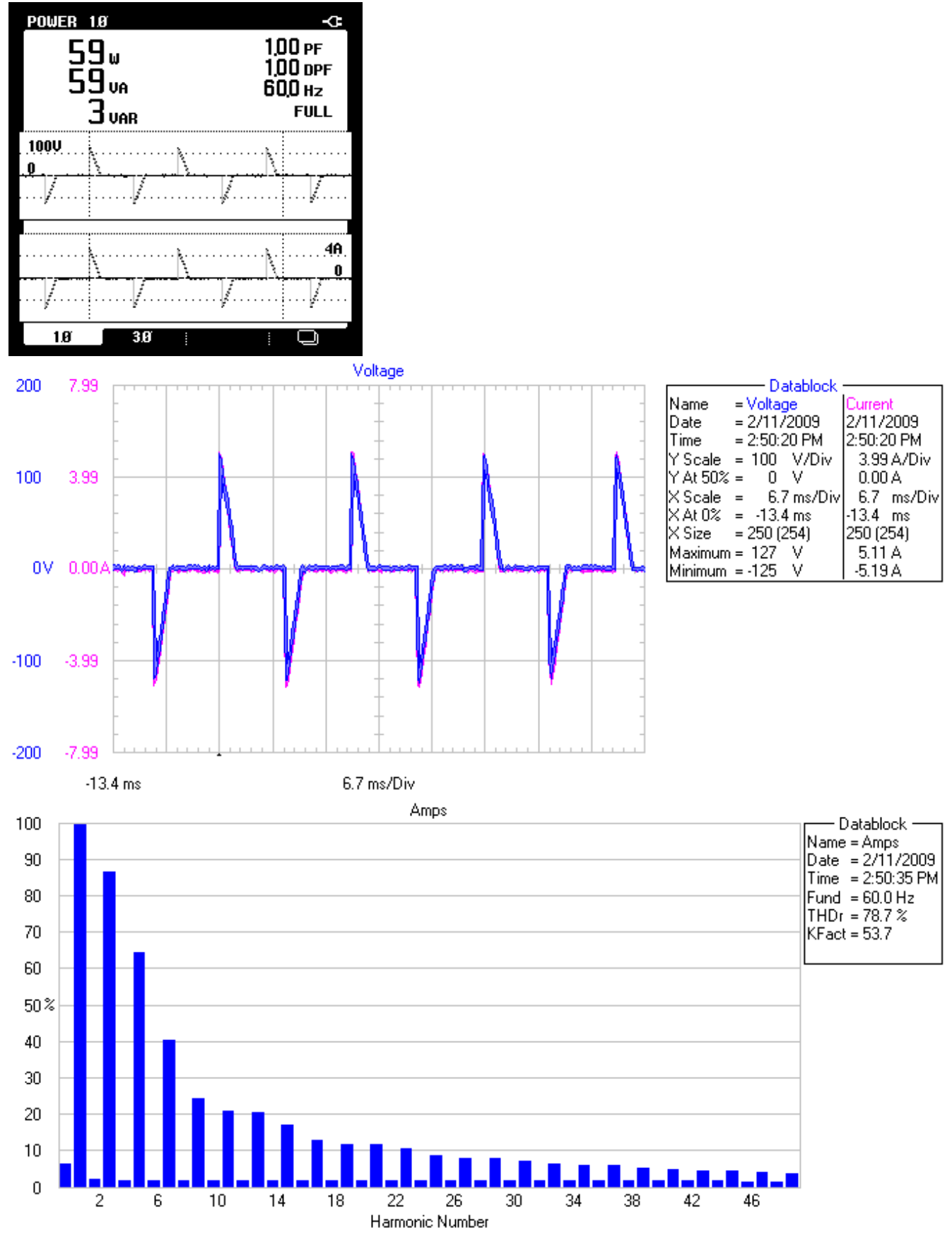

Switch: Lutron model 81000, 1000-Watt

Test Instrument: Fluke Model 43B Power Quality Analyzer

Figure B.10. Power Quality Measurements for 65-Watt Incandescent R-Lamp at Minimum Power 
LumaPro, 20CFL/DIM/27, rated 1300 lumens, 10,000 hour life, 2700K, 82 CRI

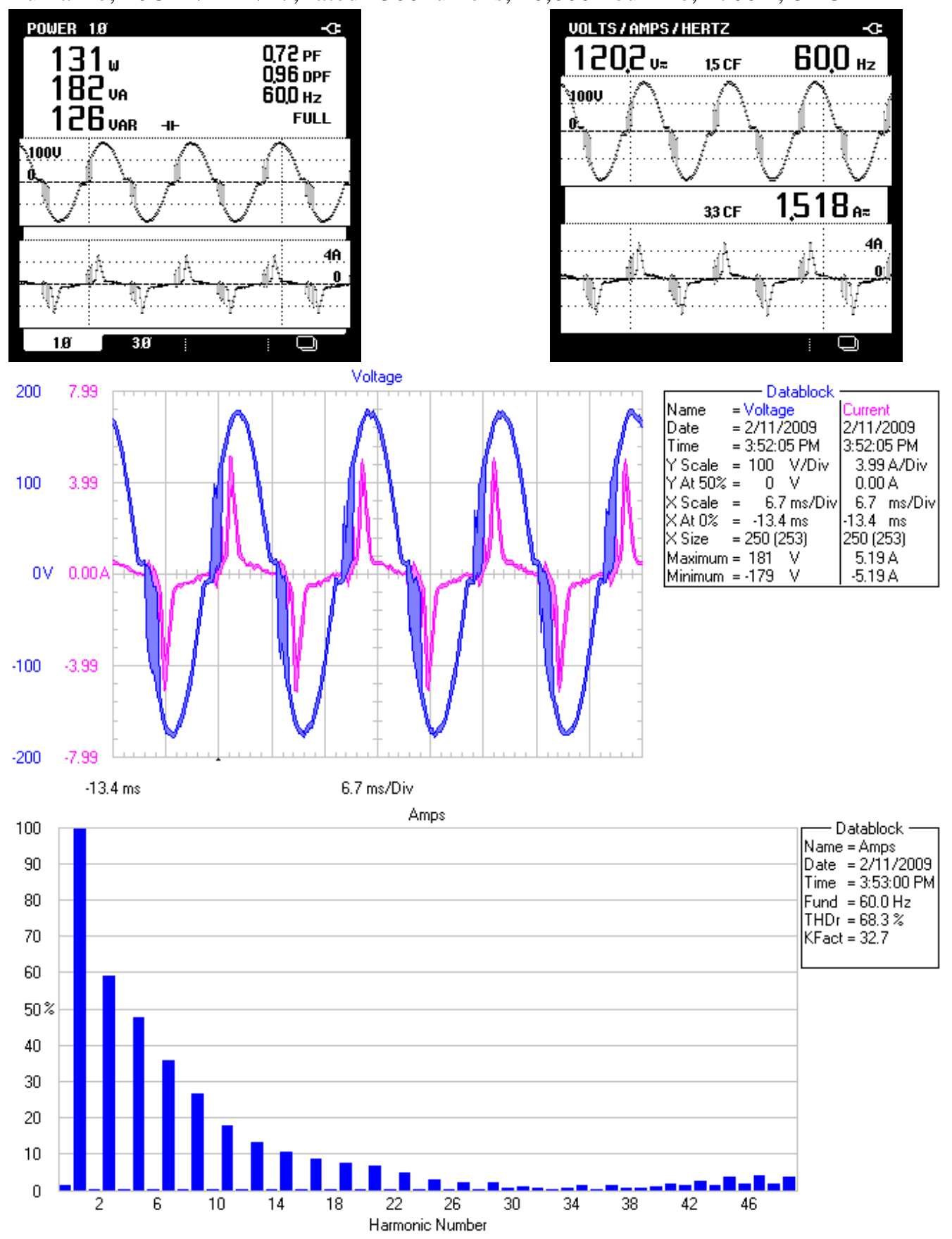

Switch: Lutron model 81000, 1000-Watt

Test Instrument: Fluke Model 43B Power Quality Analyzer

Figure B.11. Power Quality Measurements for 20-Watt Dimmable CFL at Full Power 
LumaPro, 20CFL/DIM/27, rated 1300 lumens, 10,000 hour life, 2700K, 82 CRI

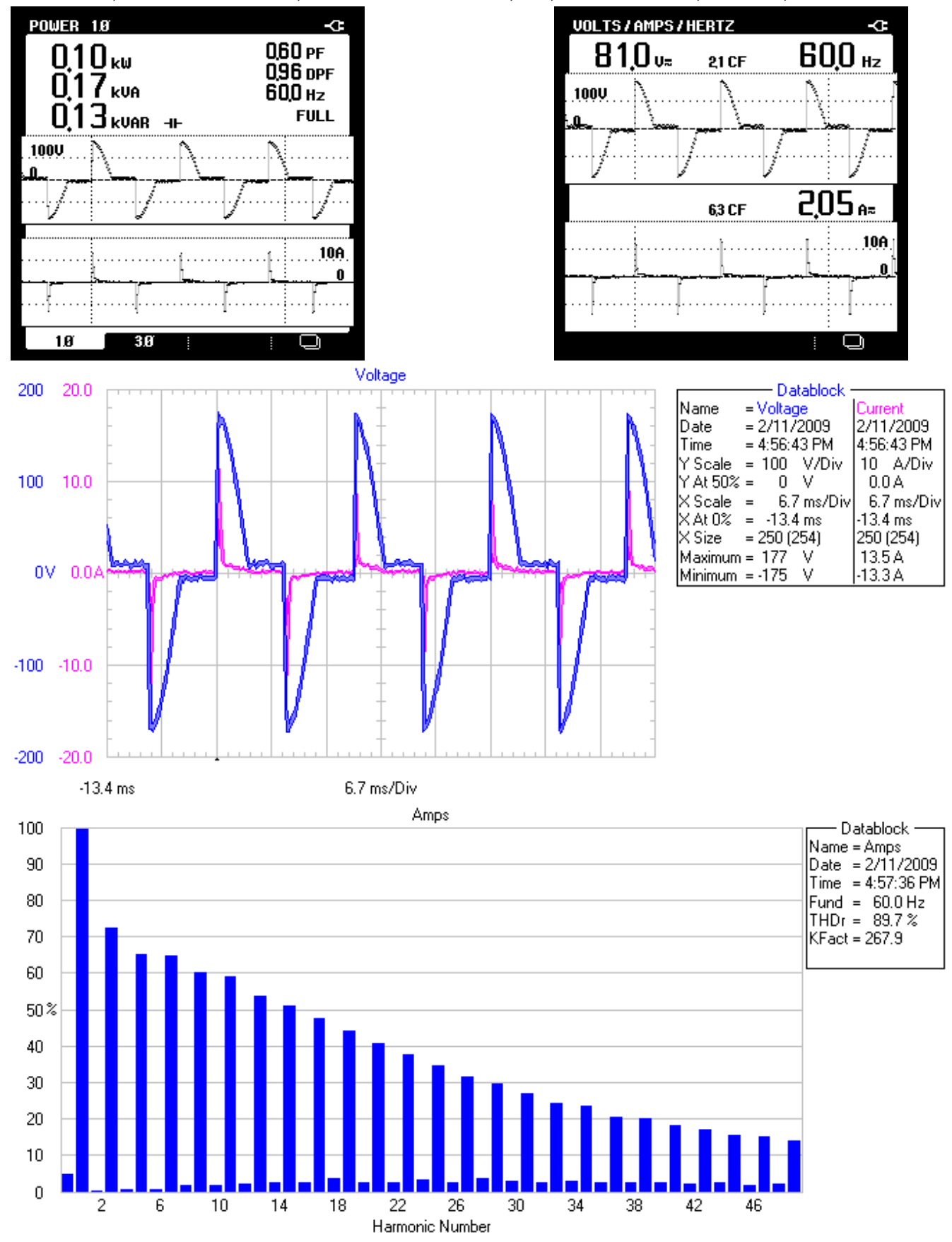

Switch: Lutron model 81000, 1000-Watt

Test Instrument: Fluke Model 43B Power Quality Analyzer

Figure B.12. Power Quality Measurements for 20-Watt Dimmable CFL at 75\% Power 
LumaPro, 20CFL/DIM/27, rated 1300 lumens, 10,000 hour life, 2700K, 82 CRI

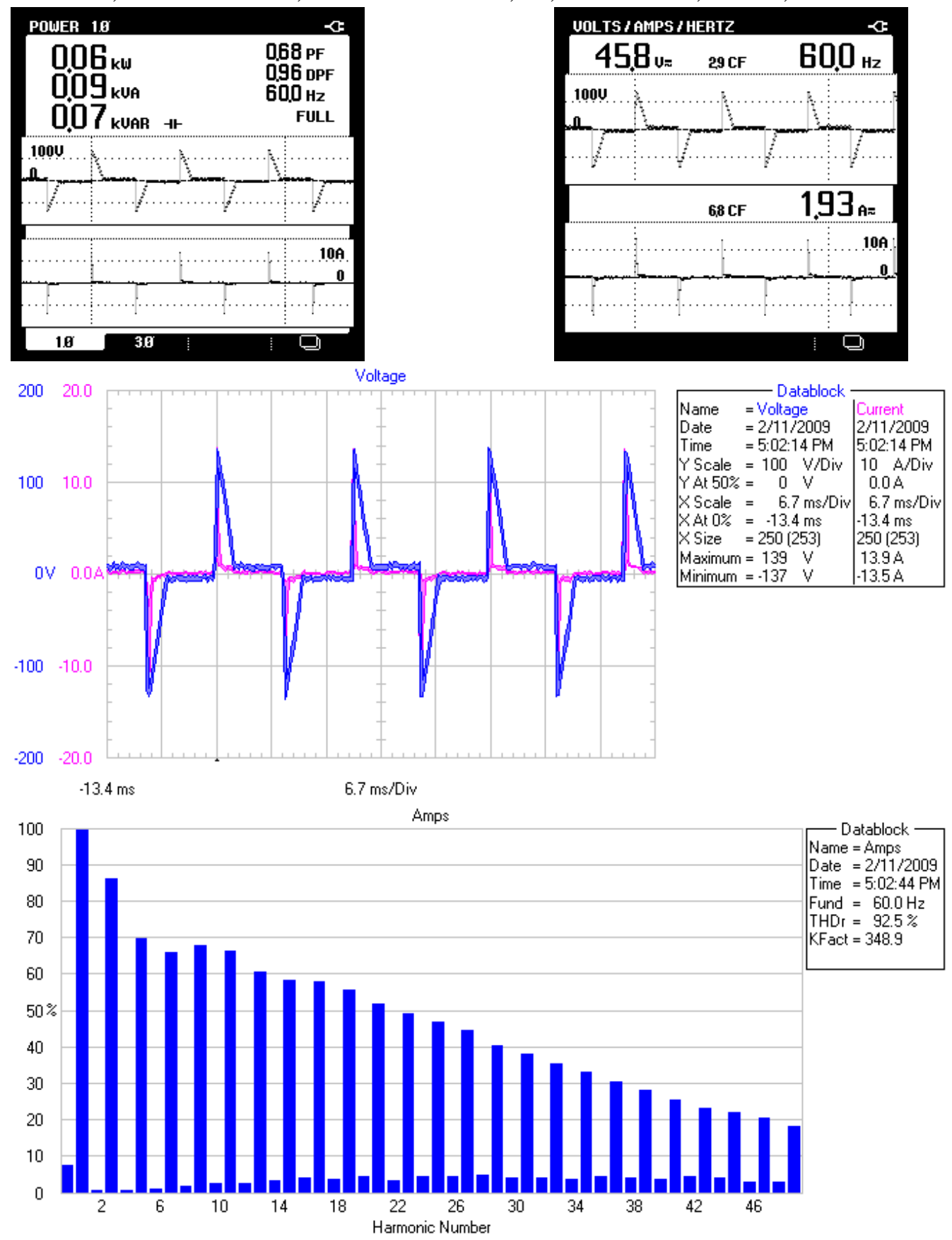

Switch: Lutron model 81000, 1000-Watt

Test Instrument: Fluke Model 43B Power Quality Analyzer

Figure B.13. Power Quality Measurements for 20-Watt Dimmable CFL at Minimum Power 
LED 15-Watt at full power

Halo, ML706830 with 494HO6 Haze Reflector, 14.8-Watts at 120-Vac, 3045K, 80 CRI
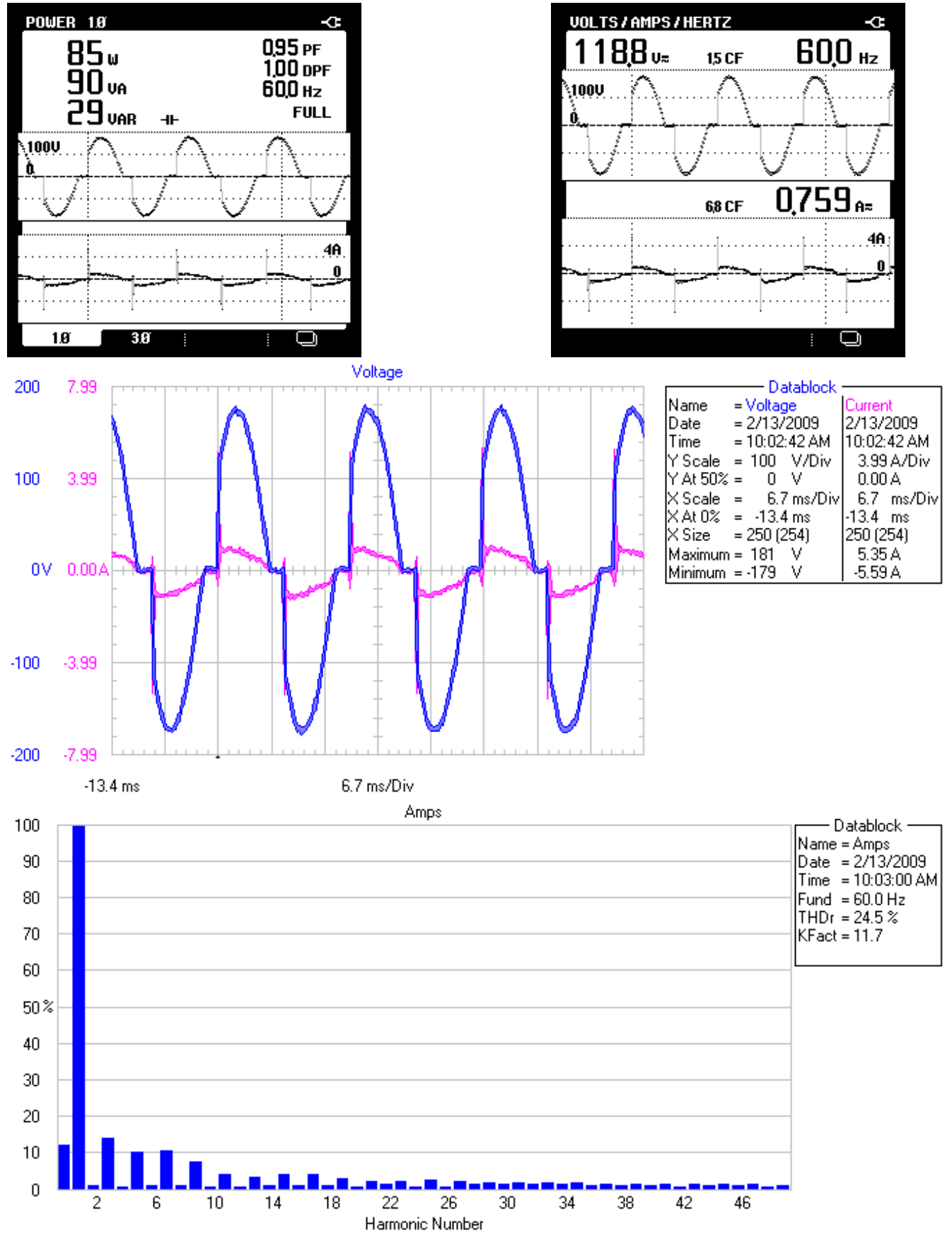

Switch: Lutron Skylark model SLV-600P, 600-Watt

Test Instrument: Fluke Model 43B Power Quality Analyzer

Figure B.14. Power Quality Measurements for 15-Watt Dimmable LED at Full Power 
Halo, ML706830 with 494HO6 Haze Reflector, 14.8-Watts at 120-Vac, 3045K, 80 CRI

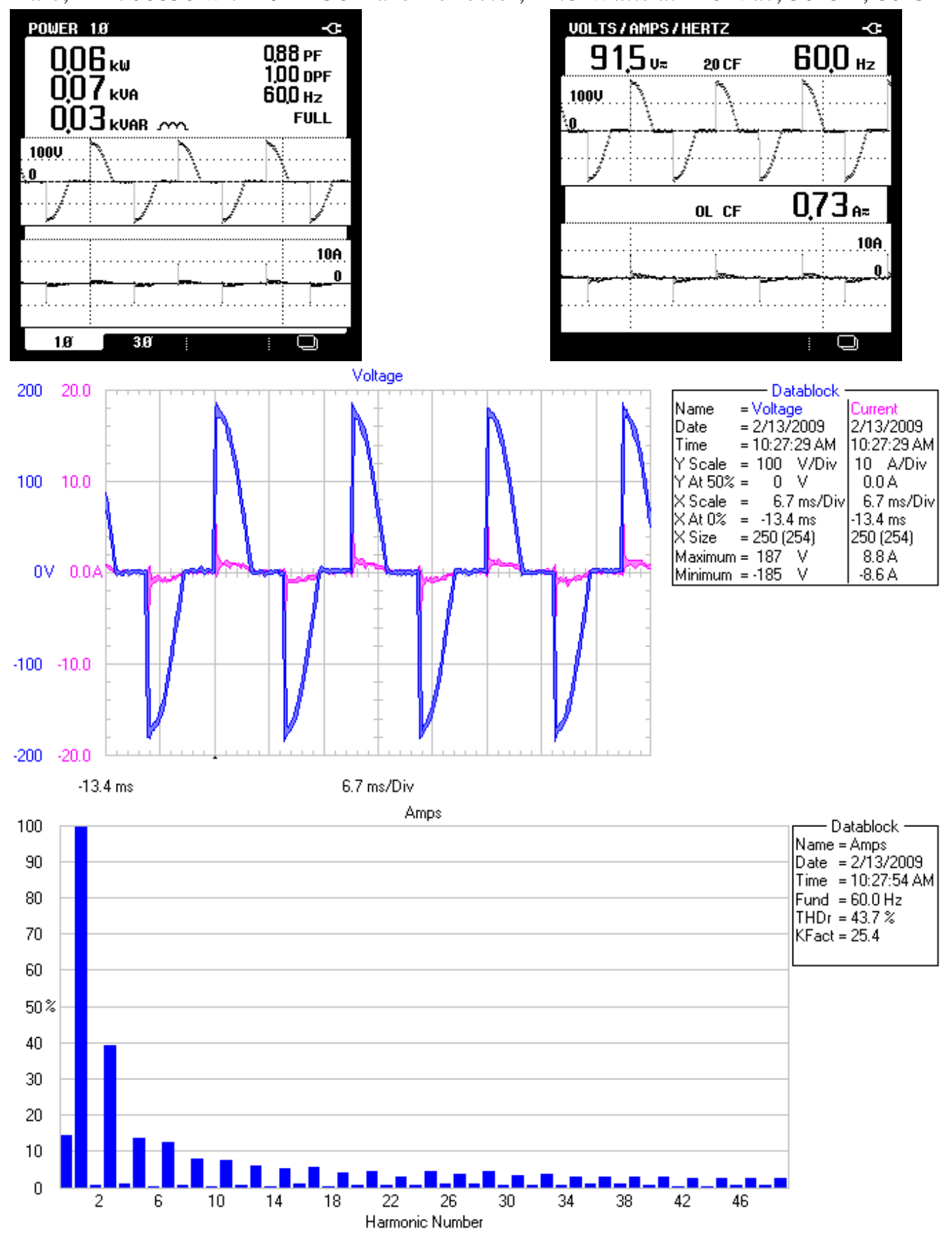

Switch: Lutron Skylark model SLV-600P, 600-Watt

Test Instrument: Fluke Model 43B Power Quality Analyzer

Figure B.15. Power Quality Measurements for 15-Watt Dimmable LED at 75\% Power 
Halo, ML706830 with 494HO6 Haze Reflector, 14.8-Watts at 120-Vac, 3045K, 80 CRI

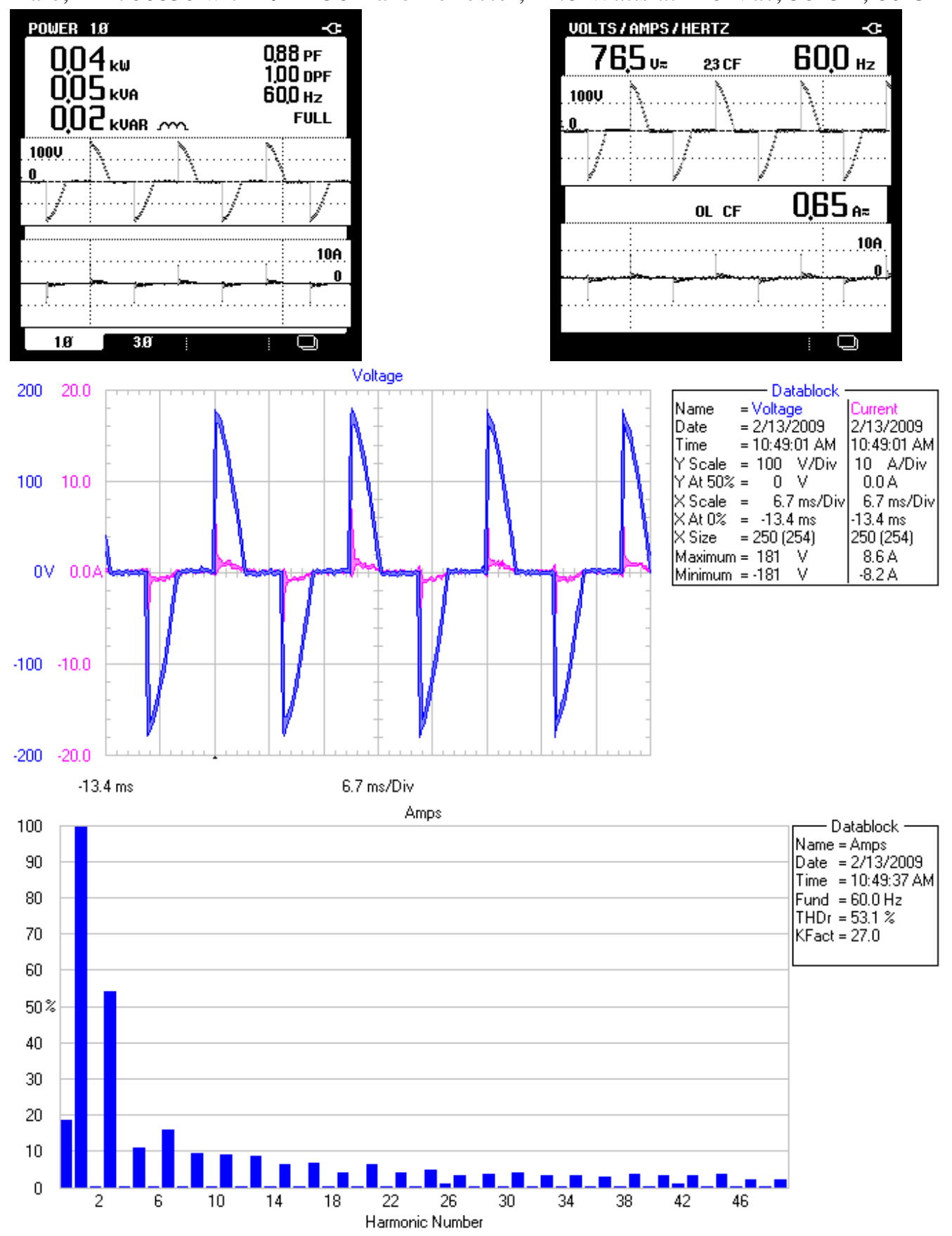

Switch: Lutron Skylark model SLV-600P, 600-Watt

Test Instrument: Fluke Model 43B Power Quality Analyzer

Figure B.16. Power Quality Measurements for 15-Watt Dimmable LED at 50\% Power 
Halo, ML706830 with 494HO6 Haze Reflector, 14.8-Watts at 120-Vac, 3045K, 80 CRI

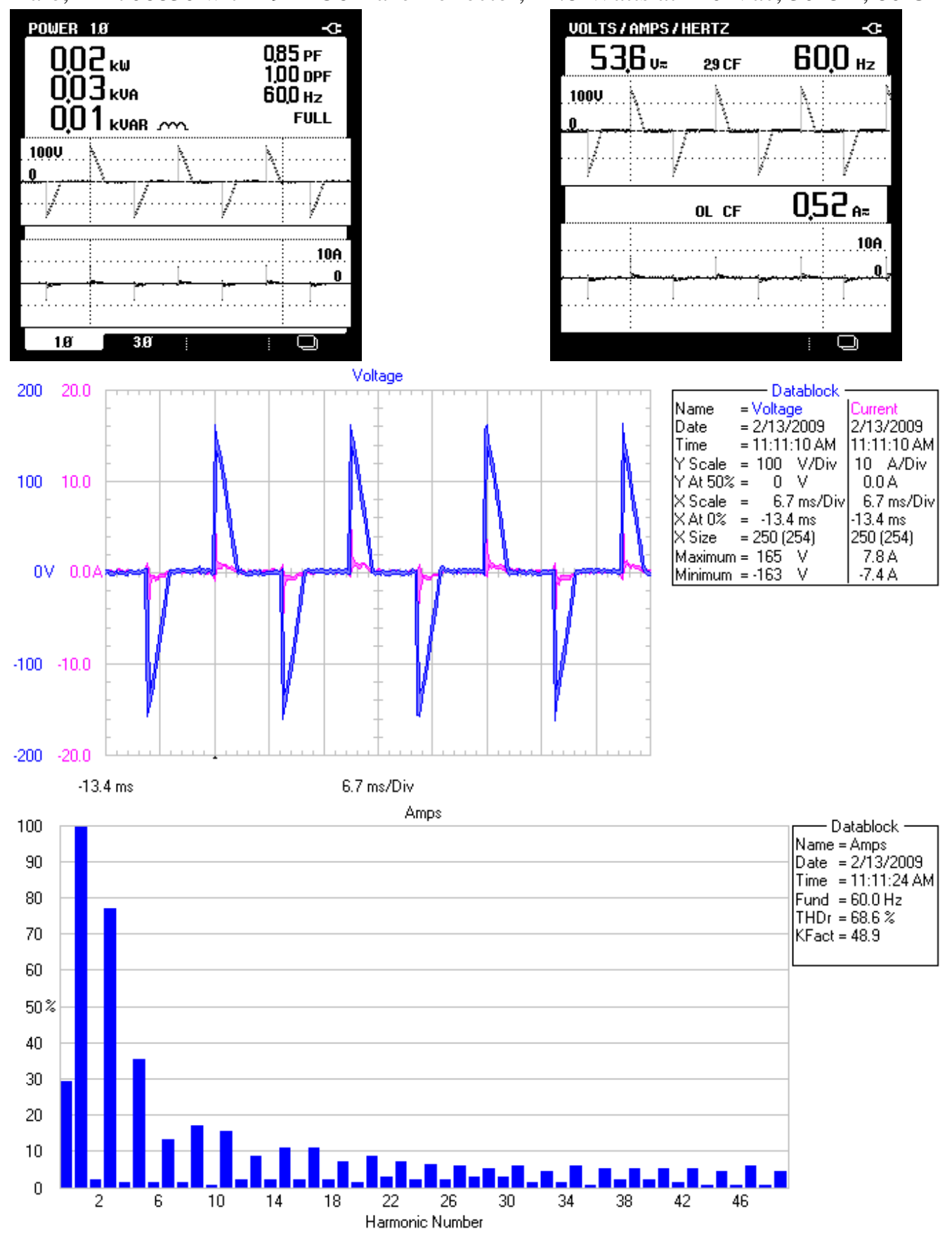

Switch: Lutron Skylark model SLV-600P, 600-Watt

Test Instrument: Fluke Model 43B Power Quality Analyzer

Figure B.17. Power Quality Measurements for 15-Watt Dimmable LED at 25\% Power 
Halo, ML706830 with 494HO6 Haze Reflector, 14.8-Watts at 120-Vac, 3045K, 80 CRI

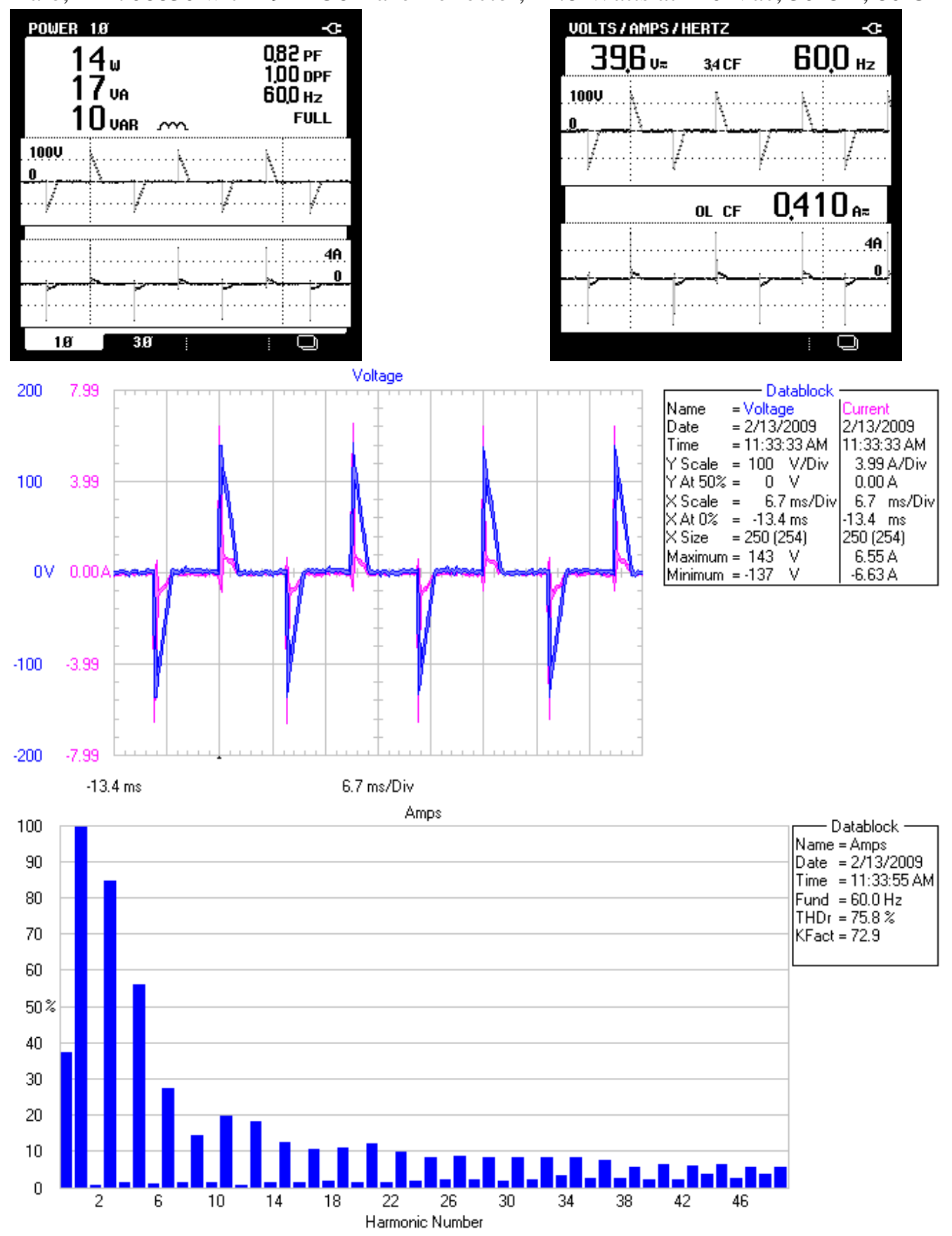

Switch: Lutron Skylark model SLV-600P, 600-Watt

Test Instrument: Fluke Model 43B Power Quality Analyzer

Figure B.18. Power Quality Measurements for 15-Watt Dimmable LED at Minimum Power 
Appendix C. Measurement Equipment 



\section{Measurement Equipment}

Illuminance Meter:

Color Meter:

Power Quality Analyzer
Minolta T-1

Minolta Chroma Meter CL-100

Fluke Model 43B 